\title{
Functional and structural deficits at accumbens synapses in a mouse model of Fragile $X$
}

\author{
Daniela Neuhofer $1,2,3 \dagger$, Christopher M. Henstridge ${ }^{4 \dagger}$, Barna Dudok ${ }^{4,5}$, Marja Sepers ${ }^{6}$, \\ Olivier Lassalle ${ }^{1,2,3}$, István Katona ${ }^{4 *}$ and Olivier J. Manzoni ${ }^{1,2,3 *}$
}

1 INSERM U901, Marseille, France, ${ }^{2}$ INMED, Marseille, France, ${ }^{3}$ Université de Aix-Marseille, UMR S901, Marseille, France, ${ }^{4}$ Momentum Laboratory of Neurobiology, Institute of Experimental Medicine, Hungarian Academy of Sciences, Budapest, Hungary, ${ }^{5}$ School of Ph.D. Studies, Semmelweis University, Budapest, Hungary, ${ }^{6}$ Department of Psychiatry, University of British Columbia, Vancouver, Canada

\section{OPEN ACCESS}

Edited by:

Hansen Wang,

University of Toronto, Canada

Reviewed by:

Claudia Bagni,

Catholic University of Leuven,

Belgium

Annalisa Scimemi,

SUNY Albany, USA

Arianna Maffei,

SUNY Stony Brook, USA

${ }^{*}$ Correspondence: István Katona, Momentum Laboratory of Neurobiology, Institute of Experimental Medicine, Hungarian

Academy of Sciences, $\mathrm{H}-1083$

Budapest, Hungary

katona@koki.hu;

Olivier J. Manzoni, INSERM U901, INMED, Parc Scientifique de Luminy,

163 avenue de Luminy, 13273 Marseille Cedex 09, France olivier.manzoni@inserm.fr

${ }^{\dagger}$ These authors have contributed equally to this work.

Received: 19 November 2014 Accepted: 07 March 2015 Published: 26 March 2015

Citation: Neuhofer D, Henstridge CM, Dudok B, Sepers M, Lassalle O, Katona I and Manzoni OJ (2015) Functional and structural deficits at accumbens synapses in a mouse model of Fragile $X$

Front. Cell. Neurosci. 9:100 doi: 10.3389/fncel.2015.00100
Fragile $X$ is the most common cause of inherited intellectual disability and a leading cause of autism. The disease is caused by mutation of a single $X$-linked gene called fmr 1 that codes for the Fragile $X$ mental retardation protein (FMRP), a $71 \mathrm{kDa}$ protein, which acts mainly as a translation inhibitor. Fragile $X$ patients suffer from cognitive and emotional deficits that coincide with abnormalities in dendritic spines. Changes in spine morphology are often associated with altered excitatory transmission and long-term plasticity, the most prominent deficit in fmr1-/y mice. The nucleus accumbens, a central part of the mesocortico-limbic reward pathway, is now considered as a core structure in the control of social behaviors. Although the socio-affective impairments observed in Fragile $X$ suggest dysfunctions in the accumbens, the impact of the lack of FMRP on accumbal synapses has scarcely been studied. Here we report for the first time a new spike timing-dependent plasticity paradigm that reliably triggers NMDAR-dependent long-term potentiation (LTP) of excitatory afferent inputs of medium spiny neurons (MSN) in the nucleus accumbens core region. Notably, we discovered that this LTP was completely absent in fmr1-/y mice. In the fmr1-/y accumbens intrinsic membrane properties of MSNs and basal excitatory neurotransmission remained intact in the fmr1-/y accumbens but the deficit in LTP was accompanied by an increase in evoked AMPA/NMDA ratio and a concomitant reduction of spontaneous NMDAR-mediated currents. In agreement with these physiological findings, we found significantly more filopodial spines in $f m r 1-/ y$ mice by using an ultrastructural electron microscopic analysis of accumbens core medium spiny neuron spines. Surprisingly, spine elongation was specifically due to the longer longitudinal axis and larger area of spine necks, whereas spine head morphology and postsynaptic density size on spine heads remained unaffected in the fmr1-/y accumbens. These findings together reveal new structural and functional synaptic deficits in Fragile $X$.

Keywords: synaptic plasticity, spike timing-dependent plasticity, accumbens, Fragile X, dendritic spines, autism 


\section{Introduction}

Fragile $\mathrm{X}$ is the most common monogenetic cause of inherited intellectual disability and a leading cause of autism. The disease is caused by mutation of a single X-linked gene called fmr 1 (Verkerk et al., 1991). The Fragile X mental retardation protein (FMRP) is a $71 \mathrm{kDa}$ protein which regulates the transport and translation of more than 850 mRNAs in the brain and especially in synapses (Ronesi and Huber, 2008; Darnell et al., 2011; Maurin et al., 2014). Fragile X patients suffer from intellectual disability and neuropsychiatric problems such as social anxiety, attention-deficit hyperactivity and sensory hypersensitivity (de Vries et al., 1998; Tranfaglia, 2011). The fmr1-/y mice display behavioral phenotypes that correspond to many of the symptoms found in FRAX patients (Kooy, 2003). One key pathological feature of the disease is the presence of distinctive spine abnormalities, which have been found in the post-mortem tissue of Fragile X patients as well as in $f m r 1-/ y$ mice (Comery et al., 1997; Irwin et al., 2000, 2001). This morphological abnormality coincides with altered synaptic plasticity, which was first described at hippocampal excitatory synapses, in the form of exaggerated protein translation- and mGluR-dependent long-term depression (mGluR-LTD; Bear et al., 2004). Since then many different forms of brain region-specific and agedependent deficits in synaptic plasticity have been described (for reviews see Martin and Huntsman, 2012; Sidorov et al., 2013).

The nucleus accumbens, the ventral part of the striatum, has been extensively studied in the context of rewardrelated behaviors (Gipson et al., 2014). Its role in rewarding social behaviors and social interactions has recently been highlighted (Wallace et al., 2009; Dölen et al., 2013; Gunaydin et al., 2014). Although altered social behavior and interactions are core symptoms in Fragile $\mathrm{X}$ patients, how morphological and neurophysiological maladaptation of accumbal synapses participate in the disease remains poorly understood (Jung et al., 2012). This is critically important, however, in light of the key physiological regulatory function of the excitatory afferent pathways and their synaptic integration and persistent modifications in the control of social reward-related and goal-directed behaviors (McGinty and Grace, 2008; Sesack and Grace, 2010; Grueter et al., 2012; Papp et al., 2012). The ultrastructural changes accompanying synaptic plasticity deficits in this brain region in the mouse model of Fragile $\mathrm{X}$ syndrome remain also obscure. Thus far, only one study suggested impaired dendrites and spines in the accumbens of $f m r 1-/ y$ mice (Jung et al., 2012). A detailed ultrastructural analysis of the morphological parameters of dendritic spines and their afferent excitatory synapses on spine heads are still lacking in the fmr1-/y mice.

In this study, we aimed to identify previously undisclosed alterations in long-term potentiation (LTP) and spine architecture at accumbens excitatory synapses in $\mathrm{fmrl-} / \mathrm{y}$ mice. We discovered an impaired spike-timing-dependent LTP in medium spiny neurons located in the accumbens core region of $f m r 1-/ y$ mice, which was associated with a higher ratio of evoked synaptic AMPAR- and NMDARmediated currents. In accordance with the idea that functional deficits occur together with structural alterations of the synapse, an ultrastructural analysis by electron microscopy revealed marked alterations in postsynaptic spine number and structure. Most importantly, long torturous spines were much more common in the accumbens core region of $f m r 1-/ y$ mice, which was the result of a specific elongation of the spine neck, but not the spine head. Together these data shed new light on the functional and structural alterations in the accumbens of $f m r 1-/ y$ mice and suggest new synaptic substrates for some of the behavioral deficits observed in Fragile X.

\section{Materials and Methods}

\section{Animals}

Animals were treated in compliance with the European Communities Council Directive (86/609/EEC) and the United States National Institutes of Health Guide for the Care and Use of Laboratory Animals. All animals were housed, grouped and acclimated to laboratory conditions for 4 days before experiments with $12 \mathrm{~h}$ light/dark cycles and access to food and water ad libitum.

\section{Slice Preparation and Electrophysiology Slice Preparation}

Adult male fmr1-/y mice on a C57Bl6/J genetic background aged between 60 and 180 postnatal days were used, with wildtype littermates used as control group (Jung et al., 2012). They were anesthetized with isoflurane and decapitated according to institutional regulations. The brain was sliced $(300 \mu \mathrm{m})$ in the coronal plane with a vibratome (Integraslice, Campden Instruments, Loughborough, UK) in a sucrose-based solution at $4^{\circ} \mathrm{C}$ (in mM: $87 \mathrm{NaCl}, 75$ sucrose, 25 glucose, $2.5 \mathrm{KCl}, 4 \mathrm{MgCl}_{2}$, $0.5 \mathrm{CaCl}_{2}, 23 \mathrm{NaHCO}_{3}$ and $\left.1.25 \mathrm{NaH}_{2} \mathrm{PO}_{4}\right)$. Immediately after cutting, slices were stored for $1 \mathrm{~h}$ at $32^{\circ} \mathrm{C}$ in a low calcium artificial cerebrospinal fluid (low $\mathrm{Ca}^{2+} \mathrm{ACSF}$ ) that contained (in $\mathrm{mM}$ ): $130 \mathrm{NaCl}, 11$ Glucose, $2.5 \mathrm{KCl}, 2.4 \mathrm{MgCl}_{2}, 1.2 \mathrm{CaCl}_{2}, 23$ $\mathrm{NaHCO}_{3}, 1.2 \mathrm{NaH}_{2} \mathrm{PO}_{4}$, and was equilibrated with $95 \% \mathrm{O}_{2} / 5 \%$ $\mathrm{CO}_{2}$ and then at room temperature until the time of recording.

\section{Electrophysiology}

Whole cell patch-clamp of visualized MSN and field potential recordings were made in coronal slices containing the ventral striatum as previously described (Robbe et al., 2002c). Recordings were made in the medial ventral accumbens core close to the anterior commissure (Robbe et al., 2002c).

For recording, slices were placed in the recording chamber and superfused (1.5-2 $\mathrm{ml} / \mathrm{min}$ ) with ACSF (same as low $\mathrm{Ca}^{2+}$ ACSF with the following exception: $2.4 \mathrm{mM} \mathrm{CaCl}_{2}$ and $\left.1.2 \mathrm{mM} \mathrm{MgCl}_{2}\right)$. All experiments were done at $32^{\circ} \mathrm{C}$. The superfusion medium contained picrotoxin $(100 \mu \mathrm{M})$ to block gamma-aminobutyric acid types A (GABA-A) receptors. All drugs were added at the final concentration to the superfusion medium. For whole cell patch-clamp experiments, neurons were visualized using an upright microscope with infrared 
illumination. The intracellular solution was based on $\mathrm{K}^{+}$ gluconate (in $\mathrm{mM}: 145 \mathrm{~K}^{+}$gluconate, $3 \mathrm{NaCl}, 1 \mathrm{MgCl}_{2}$, 1 EGTA, $0.3 \mathrm{CaCl}_{2}, 2 \mathrm{Na}_{2}{ }^{+}$ATP, and $0.3 \mathrm{Na}^{+}$GTP, 0.2 cAMP, buffered with 10 HEPES. To quantify the AMPA/NMDA ratio we used a $\mathrm{CH}_{3} \mathrm{O}_{3}$ SCs-based solution (in mM:128 $\mathrm{CH}_{3} \mathrm{O}_{3} \mathrm{SCs}$, $20 \mathrm{NaCl}, 1 \mathrm{MgCl}_{2}, 1$ EGTA, $0.3 \mathrm{CaCl}_{2}, 2 \mathrm{Na}_{2}{ }^{+} \mathrm{ATP}$, and $0.3 \mathrm{Na}^{+}$GTP, 0.2 cAMP, buffered with 10 HEPES, pH 7.2, osmolarity 290-300 mOsm. The $\mathrm{pH}$ was adjusted to 7.2 and osmolarity to 290-300 mOsm. Electrode resistance was 4-6 MOhms.

A $-2 \mathrm{mV}$ hyperpolarizing pulse was applied before each evoked EPSC in order to evaluate the access resistance and those experiments in which this parameter changed $>25 \%$ were rejected. Access resistance compensation was not used and acceptable access resistance was $<30 \mathrm{MOhms}$. The potential reference of the amplifier was adjusted to zero prior to breaking into the cell. Cells were held at $-76 \mathrm{mV}$. Current-voltage (I-V) curves were made by a series of hyperpolarizing to depolarizing current steps immediately after breaking into the cell. Membrane resistance was estimated from the $\mathrm{I}-\mathrm{V}$ curve around resting membrane potential (Kasanetz and Manzoni, 2009).

Whole cell patch-clamp recordings were performed with an Axopatch-200B amplifier. Data were low pass filtered at $2 \mathrm{kHz}$, digitized (10 kHz, DigiData 1440A, Axon Instrument), collected using Clampex 10.2 and analyzed using Clampfit 10.2 (all from Molecular Device, Sunnyvale, USA). Both fEPSP area and amplitude were analyzed. Stimulation was performed with a glass electrode filled with ACSF and placed $\sim 200 \mu \mathrm{m}$ in the dorsalmedial direction of the recorded cell. The stimulus intensity was adjusted around $60 \%$ of maximal intensity after performing an input-output curve (baseline EPSC amplitudes ranged between 50-150 pA). Stimulation frequency was set at $0.1 \mathrm{~Hz}$.

STDP induction: The STDP induction protocol was performed in the current clamp configuration. The prepost STDP protocol consisted of the baseline electrical stimulation followed by a supra-threshold depolarization of the recorded neuron to elicit an action potential. The time of the depolarization was adjusted for each cell to achieve a delay of $25 \mathrm{~ms}$ between the beginning of the EPSP and the action potential. This protocol was then delivered 60 times at $0.1 \mathrm{~Hz}$.

E-S Coupling: For ES-Coupling analysis, ten traces were recorded for each stimulus. The value of ES-Coupling obtained for each animal was calculated by averaging the spiking probability corresponding to each class of EPSP slope. EPSP slopes were measured during the first $2 \mathrm{~ms}$, sorted in $0.5 \mathrm{mV} / \mathrm{ms}$ bins, and the firing probability was determined for each bin.

Spontaneous EPSCs (sEPSCs) were recorded at $-76 \mathrm{mV}$ (AMPAR-mediated sEPCS) or $+40 \mathrm{mV}$ (NMDAR-mediated sEPSC) in whole cell voltage-clamp configuration using Axoscope 10 (Molecular Devices). sEPSCs were filtered at $2 \mathrm{kHz}$ and digitized at $20 \mathrm{kHz}$. sEPSCs amplitude and interinterval time were analyzed with Axograph $\mathrm{X}$ using a double exponential template: $f(t)=\exp (-t /$ rise $)+\exp (-t /$ decay $)$, rise $=0.5 \mathrm{~ms}$ or $3 \mathrm{~ms}$ and decay $=3 \mathrm{~ms}$ or $10 \mathrm{~ms}$, for AMPARand NMDAR-mediated EPSCs, respectively. The threshold of amplitude detection was set at $5 \mathrm{pA}$ or $2 \mathrm{pA}$ for AMPAR- and NMDAR-mediated EPSCs, respectively.

\section{Data Acquisition and Analysis}

The magnitude of plasticity was calculated 20-30 min after the potentiation protocol as percentage of baseline responses. To determine the AMPA/NMDA ratio, the cells were voltage clamped to $+40 \mathrm{mV}$ and a stable dual response (AMPA + NMDA current) to afferent stimulation was recorded. The AMPAR EPSC was isolated after bath application of the NMDAR antagonist D-2-amino- 5-phosphonovaleric acid (D-APV, $50 \mu \mathrm{M})$. The NMDAR EPSC was obtained by digital subtraction of the AMPAR EPSC from the dual response. Spontaneous EPSCs were analyzed with Axograph X (Axograph). Statistical analysis of data was performed with GraphPad Prism (GraphPad Software Inc., La Jolla, CA) using tests indicated in the main text after outlier subtraction. All values are given as mean \pm standard error and statistical significance was set at ${ }^{*} p<0.05$ and ${ }^{* *} p<0.01$.

\section{Anatomy \\ Animals, Perfusion and Preparation of Tissue Sections}

All animal experiments were approved by the Hungarian Committee of the Scientific Ethics of Animal Research (license number: XIV-1-001/2332-4/2012), and were carried out according to the Hungarian Act of Animal Care and Experimentation (1998, XXVIII, Section 243/1998), which are in accordance with the European Communities Council Directive of 24 November 1986 (86/609/EEC; Section 243/1998). All efforts were made to minimize pain and suffering and to reduce the number of animals used. Adult male $\mathrm{C} 57 \mathrm{BL} / 6 \mathrm{~J}$ mice [three wild-type and three $f m r 1-/ y$ mice ( 8 weeks old) were deeply anesthetized with a mixture of ketamine-xylazine $(25 \mathrm{mg} / \mathrm{ml}$ ketamine, $5 \mathrm{mg} / \mathrm{ml}$ xylazine, $0.1 \% \mathrm{w} / \mathrm{w}$ pipolphen in $\mathrm{H}_{2} \mathrm{O}$; $1 \mathrm{ml} / 100$ g, i.p.). Animals were then perfused transcardially with $0.9 \%$ saline for $2 \mathrm{~min}$, followed by $100 \mathrm{ml}$ of fixative containing $4 \%$ paraformaldehyde and $0.1 \%$ glutaraldehyde in $0.1 \mathrm{M}$ phosphate buffer (PB), $\mathrm{pH}$ 7.4, for $20 \mathrm{~min}$. After perfusion, the brain was removed from the skull, cut into blocks, postfixed for $2 \mathrm{~h}$ and washed in $\mathrm{PB}$. The blocks containing the ventral striatum were sliced into $50-\mu \mathrm{m}$-thick coronal sections of the brain with a Leica VTS-1000 vibratome (Vibratome, St. Louis, MO).

\section{Immunogold Labeling}

Immunostaining does not feature in this report, however the tissue analyzed underwent immunogold labeling, which is fully detailed in our previous study (Jung et al., 2012). Briefly, after slicing and extensive washing in $0.1 \mathrm{M} \mathrm{PB}$, the sections were incubated in 10\% sucrose for $15 \mathrm{~min}$ and $30 \%$ sucrose overnight, followed by freeze thawing over liquid nitrogen four times. Subsequently, all washing steps and dilutions of the antibodies were performed in $0.05 \mathrm{M}$ tris-buffered saline (TBS), $\mathrm{pH}$ 7.4. After extensive washing in TBS, the sections were blocked in 5\% normal goat serum for $45 \mathrm{~min}$ and then incubated with an antibody against diacylglycerol lipase- $\alpha$ for a minimum of $48 \mathrm{~h}$ at $4^{\circ} \mathrm{C}$. The sections were washed extensively in TBS before incubation in $0.8 \mathrm{~nm}$ gold-conjugated goat anti-rabbit secondary antibody (1:50; AURION, Wageningen, The Netherlands), overnight at $4^{\circ} \mathrm{C}$. Then sections were silver 
intensified using the silver enhancement system R-GENT SE-EM according to the kit protocol (AURION). After development, the sections were treated with osmium tetroxide $(0.5 \%)$ in $\mathrm{PB}$ for $20 \mathrm{~min}$ at $4^{\circ} \mathrm{C}$ and dehydrated in an ascending series of ethanol and acetonitrile, before being embedded in Durcupan (ACM, Fluka, Buchs, Switzerland). During dehydration, sections were treated with $1 \%$ uranyl acetate in $70 \%$ ethanol for 15 min at $4^{\circ} \mathrm{C}$. For electron microscopy analysis, areas of interest in the ventral striatum core were removed from Durcupan embedded sections, then re-embedded and re-sectioned. Ultrathin $(60 \mathrm{~nm})$ sections were collected on Formvar-coated single-slot grids and stained with lead citrate. Electron micrographs were taken at 20,000 or $40,000 \times$ magnifications with a Hitachi 7100 electron microscope (Tokyo, Japan). An experimenter blind to the genotype of the mice performed image collection and data analysis.

\section{Synapse Density Analysis}

To assess the density of excitatory synapses in the neuropil of the accumbens, 50 electron micrographs were captured randomly at $20,000 \times$ magnification for each animal by moving two fields of view in the $x$-direction and one field of view in the $y$-direction between images. Clearly identifiable postsynaptic densities (PSDs) were used as an initial identification of putative synapses. Synapses were only counted when standard morphological parameters were met, including clear pre- and post-synaptic compartments and a distinct synaptic cleft. The number of synapses in each image was then divided by the area of each image to generate a density value of PSDs/micron squared $\left(\mathrm{PSD} / \mu \mathrm{m}^{2}\right)$. To compare the densities between genotype, a mean density value was generated for each animal from the 50 images and an unpaired Student's $t$-test performed with the 3 wildtype vs. $3 \mathrm{fmrl}-\mathrm{l} / \mathrm{y}$ mean densities. Density was also assessed using the 3D dissector approach, as described by Geinisman et al. (1996). Serial, ultrathin $60 \mathrm{~nm}$ sections were collected from all six animals and three images series captured at random at $20,000 \times$ magnification. A dissector frame with an area of $21.89 \mu \mathrm{m}^{2}$ was applied to all images and only synapses within the frame or dissected by the inclusion lines of the frame were counted. The volume of each serial image stack was $1.13 \mu \mathrm{m}^{3}$ and consisted of 6 serial sections. Each image was used initially as the reference image and then the "look up" image and synapses were only counted if found in the "look up" image and not in the reference image. Dividing all the synapses from each animal across the three stacks by the total dissector volume and expressed as PSDs $/ \mu \mathrm{m}^{3}$ generated synaptic density values. To compare the densities between genotype, a mean density value was generated for each animal and an unpaired Student's $t$-test performed with the 3 wild-type vs. $3 \mathrm{fmrl} / \mathrm{y}$ mean densities.

\section{PSD Size Analysis}

Length of PSD was measured in 100 randomly chosen synapses per animal, captured at $40,000 \times$ magnification. To ensure unbiased sampling, on average the section was imaged following two fields of view movement in the $x$-direction and one field of view in the $y$-direction between images, regardless of the shape and size of the synapse. However, synapses were only imaged when standard morphological parameters were met, including clear pre- and post-synaptic compartments and a distinct synaptic cleft. Mean lengths were generated per animal and an unpaired Student's $t$-test performed with the 3 wildtype vs. $3 \mathrm{fmrl}-/ \mathrm{y}$ mean lengths. To ensure there were no subtle differences in the spread of PSD lengths between genotypes, the data was pooled within genotypes and then binned according to size. To assess any difference in the spread of the data, a chisquared test was run. PSD area was also calculated using a $3 \mathrm{D}$ approach as described above in stacks of images $360 \mathrm{~nm}$ deep and all PSDs within found completely enclosed within this depth were analyzed ( $n=4-9$ PSDs per animal). Assuming that PSD exists as a disc, the length of the dissected PSD was measured in each serial section and multiplied by the section depth $(60 \mathrm{~nm})$ to give the PSD area for each serial image. Total PSD area $\left(\mu \mathrm{m}^{2}\right)$ was generated by adding these dissected areas together. To compare the PSD area between genotype, a mean density value was generated for each animal and an unpaired Student's $t$-test performed with the 3 wild-type vs. $3 \mathrm{fmrl}-/ \mathrm{y}$ mean values.

\section{Spine and Bouton Morphological Analysis}

To assess spine morphology, approximately 75 intact spines with a clear dendritic base and excitatory synapse were imaged at $40,000 \times$ magnification, per animal. Spine length was measured in nanometers $(\mathrm{nm})$ from the base of the neck to the tip of the head using the line measurement tool in ImageJ. Assuming spines to exist as a "ball and stick" representing the head and neck respectively, the spine head boundary was estimated by the continued convex shape of the head. Spine neck length was measured from the base of the spine to the base of the head boundary. Spine neck diameter was measured at the thinnest appearing point along the neck. Head length was measured from the base of the head boundary to the tip of the head. Spine area was calculated using ImageJ by outlining the entire spine boundary and drawing a straight line across the base of the neck. Head and neck area were calculated by outlining the neck and head boundaries using ImageJ.

To assess presynaptic alterations, 50 excitatory axospinous synapses were imaged at random, per animal. Active zone length was measured along the contour of the presynaptic terminal membrane and was determined by the weakly electron dense active zone directly appositional to the postsynaptic PSD. Total vesicle number was calculated by counting all intact vesicles in the presynaptic terminal.

For each parameter, all values from each animal were used to create a mean value per animal. The 3 wild-type values were compared to the $3 \mathrm{fmrl}-\mathrm{y}$ values using an unpaired Student's $t$-test. When mean values of individual animals belonging to the same genotype were similar the distribution of the values was compared by pooling all values per genotype and binning the data according to size. Chi-squared tests were used to analyze differences in the data spread between genotypes. To assess correlation between morphological parameters, all raw data points were used to generate a scatterplot and Pearson's correlation $R^{2}$ values were generated for each association to characterize the significance of correlation, when $p<0.05$. 
All measurements were performed using ImageJ measurement tools, figures prepared in PhotoShop and statistical tests (unpaired Student's $t$-test, Pearson's correlation, Kolmogorov-Smirnov and chi-squared test) were performed using GraphPad Prism 4.

\section{Results}

\section{NMDAR-Dependent Spike-Timing-Dependent Potentiation in Afferent Synapses of Medium Spiny Neurons in the Nucleus Acccumbens Core Region}

Numerous forms of activity-dependent LTD are expressed by accumbens synapses (Robbe et al., 2002a,b,c; Grueter et al., 2010). Reports of LTP are less common (Pennartz et al., 1993; Kombian and Malenka, 1994; Schramm et al., 2002; Schotanus and Chergui, 2008a) and complicated by the poor reliability of the induction protocols (Robbe et al., 2002b; Ji and Martin, 2012). Spike-timing-dependent plasticity (STDP) is widely considered as a physiologically relevant paradigm to trigger synaptic plasticity at central synapses (Dan and Poo, 2004; Caporale and Dan, 2008). While STDP has been well described for excitatory synapses in the dorsal striatum (Shen et al., 2008; Fino and Venance, 2010; Paille et al., 2013), a reliable LTP inducing STDP protocol for the ventral striatum is still lacking (Ji and Martin, 2012). Therefore, we first systematically searched for a consistent STDP protocol for accumbens medium spiny neurons (MSN) in adult wildtype mice based on induction parameters published a priori (Fino et al., 2005). When presynaptic stimulation was followed by a $30 \mathrm{~ms}$ postsynaptic depolarization eliciting a spike ( $\mathrm{dt}$ $=25 \mathrm{~ms}$ ), we observed a strong potentiation of synaptic efficacy ( $p=0.0134$ Wilcoxon matched pairs signed rank test, Figures 1A,B). Typically, LTP depends on the activation of postsynaptic NMDAR (Markram et al., 1997; Dan and Poo, 2004; Nevian and Sakmann, 2006). Accordingly, we found that bath application of the specific NMDAR antagonist D-APV completely prevented LTP ( $p=0.0441$, Mann-Whitney test; Figures 1C,D). Together these experiments demonstrate that accumbens excitatory synapses can reliably express NMDARdependent LTP with induction parameters specific for this synapse type.

\section{Adult fmr1-/y Accumbens Neurons Lack LTP and Show Augmented AMPA/NMDA Ratios}

Previous work from our laboratory has shown that LTD mediated by the mGluR5/endocannabinoid-signaling complex is absent in fmr1-/y mice (Jung et al., 2012). Reports of altered LTP in cortical areas abound (Padmashri et al., 2013; Sidorov et al., 2013; Boda et al., 2014; Chen et al., 2014; Franklin et al., 2014; Yang et al., 2014). In particular, a previous study by Meredith and collaborators revealed a strong impairment of STDP in the prefrontal cortex superficial pyramidal cells in $f m r 1-/ y$ mice (Meredith et al., 2007). Various impairments of LTP and LTD in the accumbens could participate in the social deficits observed in fmr1-/y mice and Fragile X patients (Oddi et al., 2013).
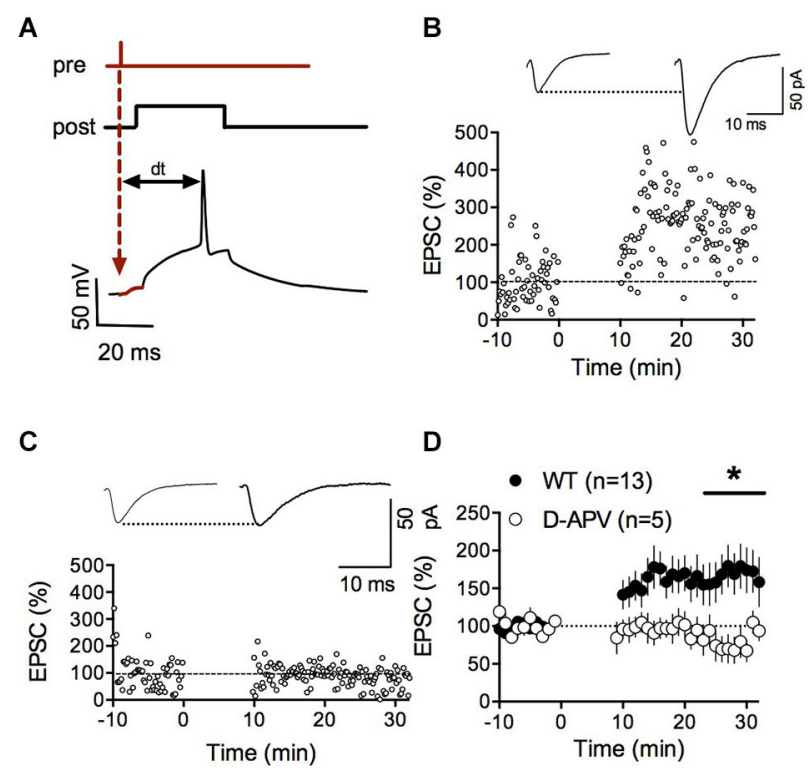

FIGURE 1 | NMDAR-dependent spike timing-dependent potentiation (LTP) in accumbens medium spiny neurons. (A) Schematic representation of the pre-post protocol used to induce LTP. After the presynaptic stimulation the postsynaptic cell was depolarized for $30 \mathrm{~ms}$ to elicit an action potential.

The time delay between presynaptic stimulation and the elicited spike was set to $25 \mathrm{~ms}$. (B) Representative experiment illustrating the induction of LTP. Inset shows EPSCS sampled during the 10 min baseline and 20 min after LTP induction respectively. (C) Representative experiment showing that LTP in WT mice was abolished by the application of the NMDAR-antagonist D-APV $(50 \mu \mathrm{M})$. (D) Summary of LTP experiments with (white circles) and without D-APV (black circles). LTP was blocked by application of $50 \mu \mathrm{M}$ D-APV ( $p=0.0441$ Mann-Whitney test).

To directly address this possibility and extend our previous work on LTD, we tested whether we could evoke LTP in $f m r 1-/ y$ mice. Using our new STDP protocol, we found that NMDARmediated LTP was ablated in accumbens MSN of $f m r 1-/ y$ mice compared to their wild type littermates ( $p=0.0415$ MannWhitney test; Figures 2A,B). In physiological and pathological conditions, long-term plasticity and the ratio of evoked synaptic AMPA/NMDA ratio often covariate (Gocel and Larson, 2012; Gipson et al., 2014). Ample evidence points toward protracted changes in the AMPA/NMDA ratio in rodent models of mental disability and autism. For example, in the in utero valproate exposure model of autism, we recently reported that adult rats had impaired prefrontal LTP and enhanced AMPA/NMDA ratio (Martin and Manzoni, 2014). Therefore, we next quantified and compared the ratio of evoked synaptic AMPAR and NMDAR currents (AMPA/NMDA ratio). We found that this index was augmented in $f m r 1-/ y$ mice compared to their wild-type littermates $(p=0.043$ Mann-Whitney test; Figures 2C,D).

\section{Intrinsic Properties and Synaptic Parameters of Accumbens Medium Spiny Neurons of Adult fmr1-/y and Wild-Type Mice}

The lack of LTP in fmrl-/y mice could be caused by alterations of intrinsic and/or firing properties of the MSNs. Thus, we 


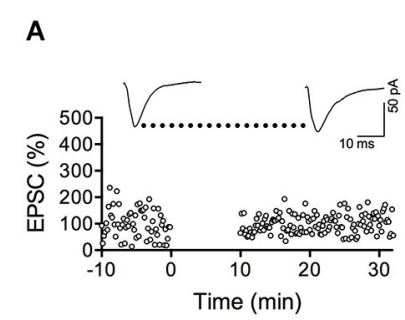

C

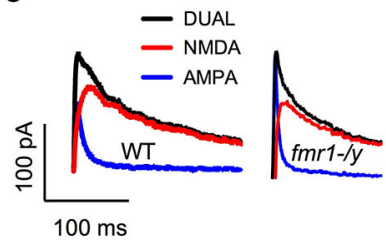

B

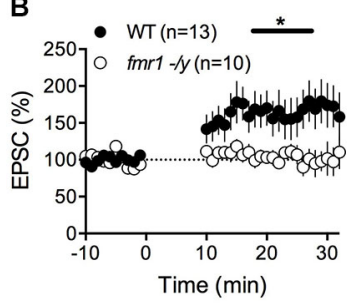

D

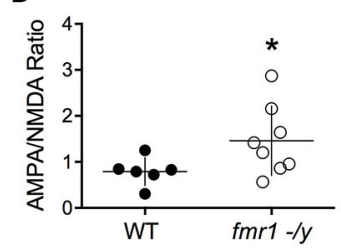

FIGURE 2 | Lack of LTP and augmented AMPA/NMDA ratio in accumbens MSN of fmr1-/y mice. (A) Representative experiment illustrating the lack of LTP in fmr1-/y mice. Inset shows EPSCs averaged over 10 min baseline and 20 min after the induction protocol respectively. (B) Averaged time-courses of LTP experiments for both genotypes. LTP was absent in fmr1-/y mice ( $p=0.0415$ Mann-Whitney test) (C) Representative current traces of a wild type (left) and fmr1-/y (right) MSN voltage clamped at $-40 \mathrm{mV}$ to illustrate the computation of $\mathrm{A} / \mathrm{N}$ ratios. Black: Dual AMPA and NMDA response. Blue: isolated AMPA response after application of d-APV $(50 \mu \mathrm{M})$. Red: NMDA response extracted via subtraction of AMPA response from the dual response. (D) A/N ratios were larger in fmr1-/y mice ( $p=0.043$, Mann-Whitney test).

compared some of the basic properties of these neurons. Independently of their genotypes, all recorded MSNs showed similar membrane response profiles in response to a series of somatic current steps as shown in superimposable $\mathrm{I}-\mathrm{V}$ plots $(p=0.2770$, two way ANOVA; Figures 3A,B). The number of action potentials in response to somatic current steps was also similar in wild-type and $f m r 1-/ y$ mice $(p=0.1272$, two way ANOVA; Figure 3C). Furthermore the lack of LTP cannot be explained by different spiking in response to the LTP protocol. The jitter i.e., the standard deviation of spike timing was $1.25 \pm 0.38 \mathrm{SD}$ and $1.308 \pm 0.93 \mathrm{SD}$ for wild-type and in fmr1- $/ y$ mice respectively ( $p=0.8503$, Student's unpaired $t$-test). We also determined the excitatory postsynaptic potential-spike coupling (or E-S coupling) to directly evaluate how synaptic excitation is integrated to generate an action potential in wildtype and fmr1-/y littermates (Thomazeau et al., 2014). We found that the E-S coupling was similar in wild-type and in fmr1-/y mice ( $p=0.1488$, two way ANOVA, Figure 3D). We conclude that the lack of FMRP in fmrl-/y mice has no major effect on excitatory synaptic integration in accumbens MSNs. More generally, the data indicate that the lack of FMRP expression did not affect on the intrinsic properties of accumbens MSNs.

We next measured field EPSPs (fEPSP) of accumbens MSNs to build input-output profiles in the two genotypes. fEPSPs evoked by electrical stimulation showed a consistent profile distribution in response to increasing stimulation intensity across different slices and mice (Figure 4A). Furthermore, inputoutput curves from wild-type and fmrl-/y littermates were
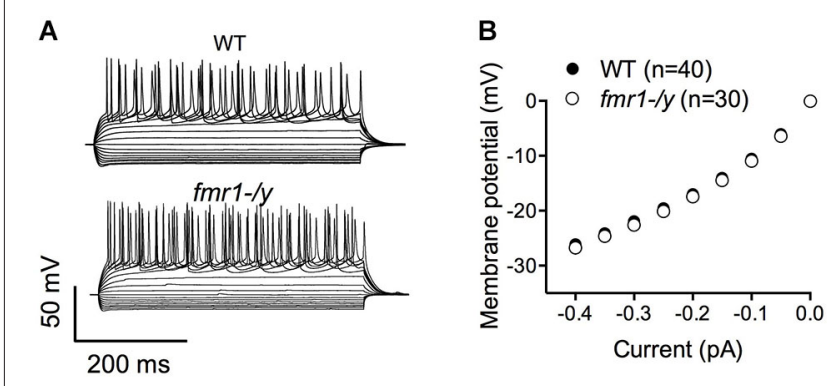

C

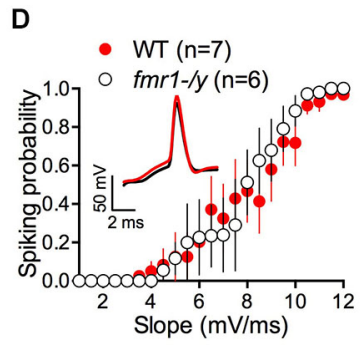

FIGURE 3 | Similar excitability profile in wild-type and fmr1-/y medium spiny neurons. (A) Representative traces of voltage responses to somatic current injections of a wild-type (upper panel, WT) and fmr1-/y (lower panel) medium spiny neuron. (B) The voltage responses to hyperpolarizing current pulses revealed no differences in input resistance or inward rectification between the two genotypes ( $p=0.2770$, two way ANOVA; WT $n=40$, black symbols; fmr1-/y $n=30$, white symbols). (C) The number of action potentials as a function of depolarizing current injections was similar $(p=0.1272$, two way ANOVA). (D) The firing probability plotted as a function of the EPSP slope revealed no changes in the Excitation-Spike coupling $(p=0.1488$, two way ANOVA; WT $n=8$, black symbols; fmr1-/y $n=5$, white symbols).

identical. The data show that the excitability of accumbens MSN synapses was unaltered (Figure 4A). Additionally, the paired pulse ratio, a form of short-term synaptic plasticity that depends on release probability of glutamate, was identical in both genotypes (Figure 4B). These data suggest that the lack of LTP is unlikely due to a reduction of the number of synapses recruited during the induction of synaptic plasticity in $f m r 1-/ y$ accumbens synapses.

Our present observation of augmented AMPA/NMDA ratio (Figures 2C,D) can be explained by synaptic insertion of additional AMPAR or/and enhanced AMPAR conductance in $f m r 1-/ y$ mice or/and reduction of NMDAR conductance. To test for this possibility, we compared quantal events by recording spontaneous AMPAR- and NMDAR-mediated EPSCs (sEPSC) in accumbens MSNs from both wild-type and fmr1-/y littermate neurons. Figures 4C,D shows the summary cumulative distribution of the amplitude in the two groups (Figure 4C). Both the distribution and the mean amplitude of spontaneous events were similar in the two genotypes. At resting membrane potential $(-70 \mathrm{mV})$, these events are principally mediated by AMPAR therefore the lack of FMRP does not appear to affect AMPAR currents in accumbens MSN. We next compared the frequency of sEPSC by comparing the cumulative distribution of the interval between events (Figure 4D). Both genotypes had a similar distribution and average inter-event intervals. 
A

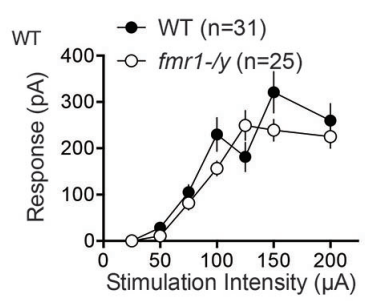

C

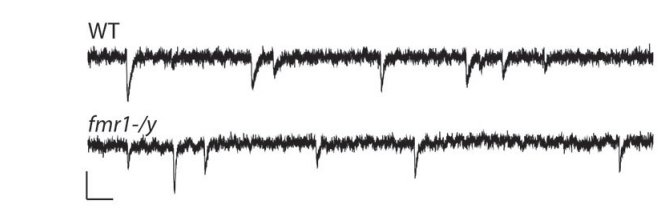

B

D
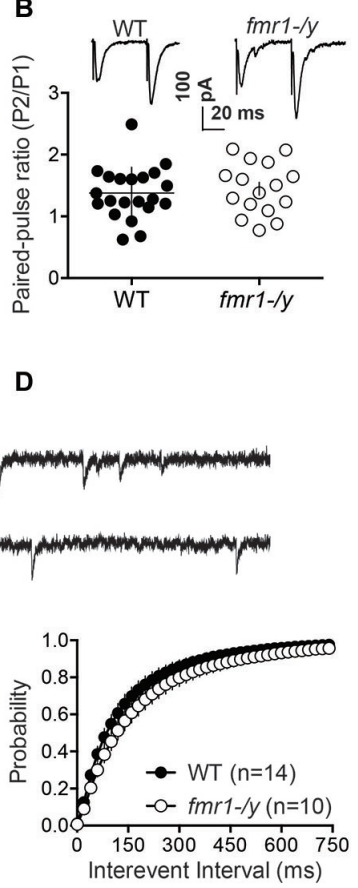

E

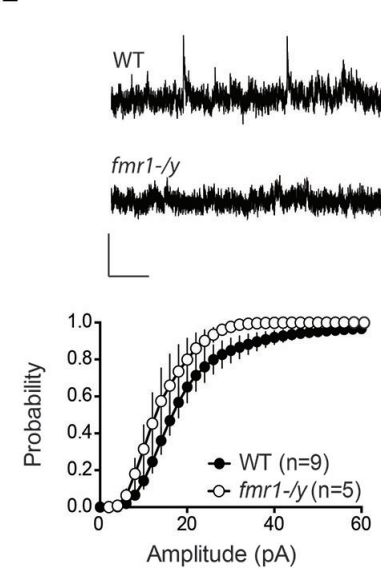

$\mathbf{F}$

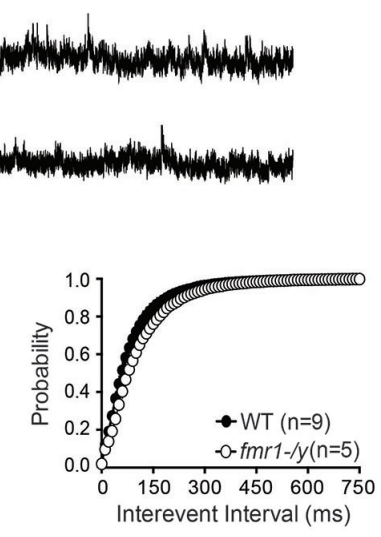

FIGURE 4 | Glutamatergic transmission parameters in the nucleus accumbens of wild-type and $\mathbf{f m r}$-/y mice. (A) Average field responses to electric stimulation of increasing intensity did not reveal a significant difference in synaptic excitability between the two genotypes. The overall excitability was not significantly different between the two genotypes $(p=0.1436$, 2-way ANOVA, the number of animals tested differed between stimulation intensities $n=14-31$, data not shown). (B) Example traces illustration the response to paired stimulations for a wild type (upper trace) and a fmr1-/y mouse (lower trace). The comparison of the median paired-pulse ratios for a stimulus interval of $50 \mathrm{~ms}$ revealed no significant difference between the two genotypes ( $p=0.4354$, WT $n=21$, fmr1-/y $n=16$, students $t$-test). (C) Sample traces from accumbens MSN clamped at $-70 \mathrm{mV}$ from wild type and fmr $1 / y$ animals (scale bar: $50 \mathrm{~ms}, 20 \mathrm{pA}$ ). The cumulative probability distribution of AMPAR sEPSCs amplitudes revealed no differences between the two genotypes (Kolmogorov-Smirnov-test; WT $n=14$, black symbols; fmr1-/y $n=10$, white symbols). (D) The cumulative probability distribution of AMPAR sEPSCs inter-event-intervals revealed no differences in spontaneous synaptic transmission between the two genotypes (Kolmogorov-Smirnov-test; WT $n=14$, black circles; fmr1-/y $n=10$, white circles). (E) Sample traces from

\section{FIGURE 4 | Continued}

accumbens MSN clamped at $+40 \mathrm{mV}$ from wild type and fmr1- $/ y$ animals (scale bar: $2 \mathrm{~s}, 50 \mathrm{pA}$ ). The cumulative probability distribution of NMDAR sEPSCs amplitudes revealed a significant difference between the two genotypes (Kolmogorov-Smirnov-test $p<0.0001$ ); WT $n=9$, black symbols; fmr1-/y $n=5$ white symbols). (F) The cumulative probability distribution of NMDAR sEPSCs inter-event-intervals revealed no differences in spontaneous synaptic transmission between the two genotypes (Kolmogorov-Smirnov-test; WT $n=9$, black circles; fmr1-/y $n=5$, white circles).

Figure $4 \mathrm{E}$ shows the summary cumulative distribution of NMDAR-sEPSC amplitude in the two genotypes. There was a shift to the left of the distribution of the amplitude of spontaneous NMDAR-mediated events in fmr1-/y mice compared to wild-type littermates. We compared the frequency of sEPSC by comparing the cumulative distribution of the interval between events (Figure 4F). Both genotypes had a similar distribution and average interval between NMDARmediated events. These data are compatible with a reduction in postsynaptic NMDAR density and/or conductance in fmr1-/y mice.

These data together with normal intrinsic properties (Figure 3) and unchanged input/output curves (Figure 4A) suggest that the profound impairment of LTP observed in fmr1-/y mice could be linked to a modification of synaptic NMDAR content.

\section{Altered Dendritic Spines of Medium Spiny Neurons in the Core Region of Nucleus Accumbens of Adult fmr1-/y Mice}

Recent results have demonstrated a tight correlation between spine morphology and synaptic strength (Araya et al., 2014; Tønnesen et al., 2014). Therefore, we next searched for structural alterations that could contribute to the impaired synaptic plasticity in fmr1- $/ y$. Dendritic spine anomalies are common in neuropsychiatric diseases and constitute a core feature of intellectual disability (Penzes et al., 2011). A common finding in both human patients and mouse models of FRAX, is the higher number of spines in multiple brain regions (He and Portera-Cailliau, 2013). In line with these findings, we found that the density of excitatory synapses innervating spine heads was significantly increased on average by $28 \%$ in the accumbens of fmr1-/y mice (Figures 5A-C). Postsynaptic density (PSD) distribution in $f m r 1-/ y$ mice $\left(0.32 \pm 0.02 \mathrm{PSD} / \mu \mathrm{m}^{2}\right)$ was significantly denser than wild-type accumbens $(0.25 \pm 0.02$ $\mathrm{PSD} / \mu \mathrm{m}^{2} ; p=0.049$ ). In contrast, PSD length was similar (wildtype $=275 \pm 3 \mathrm{~nm}$, fmrl- $/ y=289 \pm 15 \mathrm{~nm} ; p=0.42$ ) between genotypes ( $n=300$ synapses per genotype), suggesting that the increase in synapse number in the absence of FMRP is not the consequence of a potential sampling error of differentially sized PSDs (Figure 5D,E). To corroborate these observations, we also performed a 3D stereological approach to more accurately assess PSD density and size. This experiment confirmed our $2 \mathrm{D}$ analysis, showing an increased PSD density in the fmr1-/y mice (wild-type $=1.1 \pm 0.2 \mathrm{PSDs} / \mu \mathrm{m}^{2}, f m r 1-/ y=1.7 \pm 0.04$ PSDs $\left./ \mu \mathrm{m}^{2} ; p=0.046\right)$, yet confirmed the similarity in the 

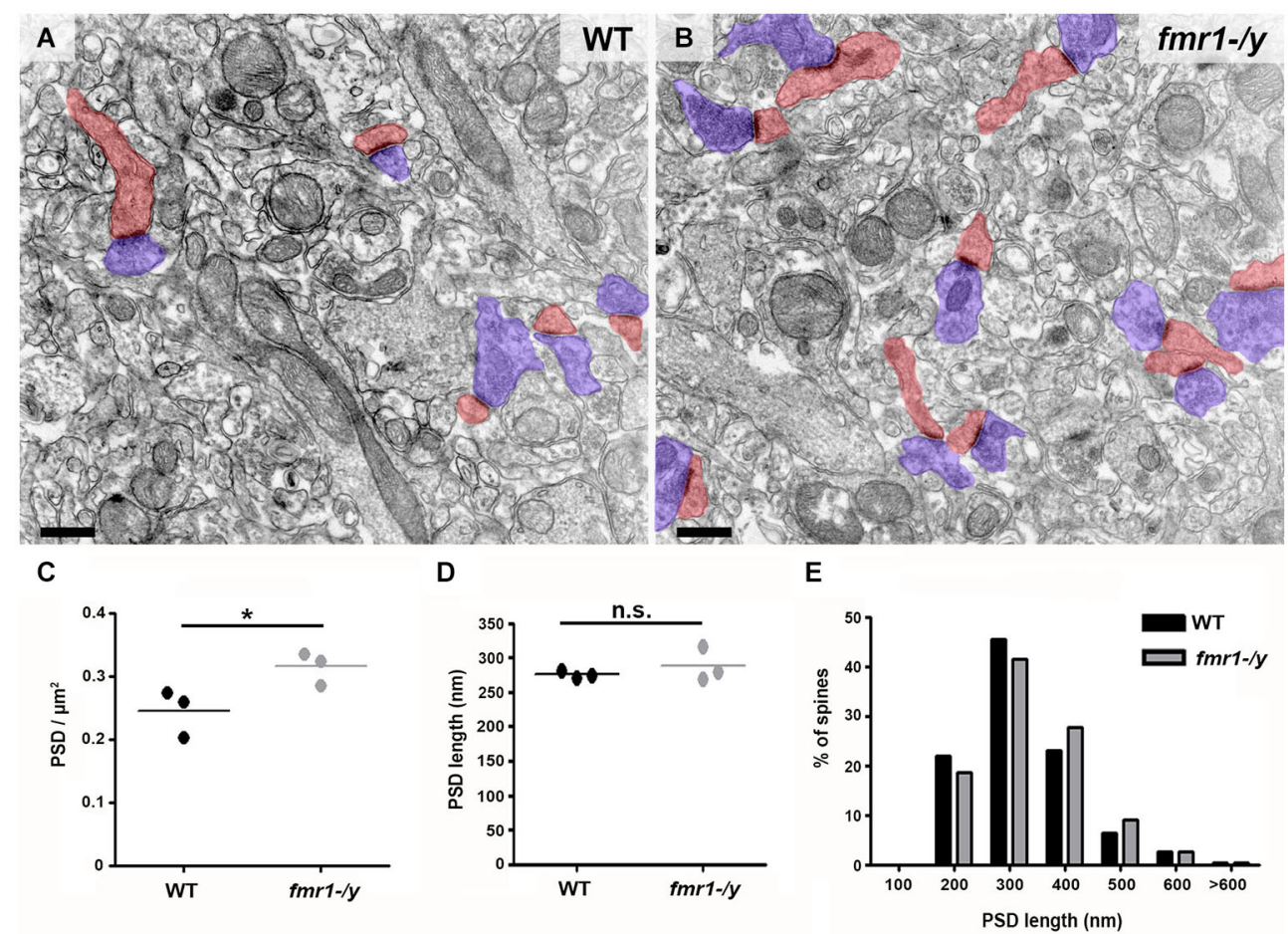

FIGURE 5 | Higher density of excitatory synapses in the accumbens of $\mathbf{f m r 1 - / y ~ m i c e . ~ E l e c t r o n ~ m i c r o g r a p h s ~ c a p t u r e d ~ i n ~ t h e ~ c o r e ~ o f ~ t h e ~}$ nucleus accumbens of wild-type (A) and fmr1-/y mice (B) reveal the scattered distribution and different density of excitatory synapses in the two genotypes. These putative glutamatergic synapses were identified by the clear presence of a PSD as well as pre- (blue) and postsynaptic (red) compartments. Scale bars $=500 \mathrm{~nm}$. (C) Mean PSD density values from
50 images per animal revealed a significant increase in excitatory synapse density in fmr1-/y mice $(n=3)$ compared to wild-type $(n=3)$. Unpaired $t$-test, $p=0.049$. (D) Mean PSD lengths measured from 100 synapses per animal $(n=3)$ revealed identical PSD length in the two genotypes. Unpaired $t$-test, $p=0.422$. (E) Separation of PSD length values into $100 \mathrm{~nm}$ bins followed by a Chi-squared test, revealed no difference in PSD length distribution, $p=0.670$.
PSD area (wild-type $=0.036 \pm 0.004 \mu \mathrm{m}^{2}$, fmrl- $/ y=0.039 \pm$ $\left.0.002 \mu \mathrm{m}^{2} ; p=0.64\right)$.

In addition to the higher spine number, we uncovered a significant increase in the total length of $f m r 1-/ y$ spines (Figures 6A-C) in the accumbens (wild-type $=856 \pm 4 \mathrm{~nm}$, fmrl-/y $=1069 \pm 20 \mathrm{~nm} ; p=0.001$ ). This manifest as a greater number of spines longer than $1 \mu \mathrm{m}$ (wild-type $=60 / 221$, fmr 1 - $/ y$ $=115 / 224$ ) and fewer spines shorter than $1 \mu \mathrm{m}$ (wild-type $=$ $161 / 221, f m r 1-/ y=109 / 224)$ in $f m r 1-/ y$ accumbens compared to wild-type (Figure 6D). Interestingly, the differences in total cross-sectional spine area did not reach statistical significance ( $p=0.157)$ between wild-type $\left(0.22 \pm 0.02 \mu \mathrm{m}^{2}\right)$ and $f m r 1-/ y$ $\left(0.27 \pm 0.02 \mu \mathrm{m}^{2}\right)$ (Figure 6E). However, when total spine area was pooled within genotypes and the Data distribution analyzed, there was a significant increase in the number of larger spines observed in $f m r 1-/ y$ mice ( $\mathrm{Chi}^{2}$ test $p=0.0002$; Figure $6 \mathrm{~F}$ ).

The observed spine elongation on average by $25 \%$ could be due to alterations in neck length, head length or both (Figure 7A). An analysis of more than 220 intact spines per genotype revealed significantly longer spine necks in the fmrl-/y mice $(684 \pm 11 \mathrm{~nm})$ compared to wild-type (518 \pm $10 \mathrm{~nm} ; p=0.0003)$, due to a significantly greater number of long spines in the fmrl-y mice (Chi ${ }^{2}$ test $p<0.0001$;
Figures 7B,C). In contrast, spine neck width was similar between genotypes (wild-type $=140 \pm 4.3 \mathrm{~nm}, \mathrm{fmrl}-/ y=130 \pm 9.8 \mathrm{~nm}$, $p=0.79)$. Neck length correlated with spine length and neck area (Figures 8A,B). Neck area correlated with spine area (Figure 8C) and, accordingly, a larger spine neck area was found in $f m r 1-/ y$ mice $\left(0.13 \pm 0.009 \mu \mathrm{m}^{2}\right)$ compared to wildtype $\left(0.099 \pm 0.005 \mu \mathrm{m}^{2} ; p=0.031\right)$ (Figure 7D). Conversely, no change in spine head length (wild-type $=338 \pm 14 \mathrm{~nm}$, fmrl-/y $=346 \pm 10 \mathrm{~nm} ; p=0.68$ ) or head area (wild-type = $\left.0.12 \pm 0.012 \mu \mathrm{m}^{2}, f m r 1-/ y=0.14 \pm 0.013 \mu \mathrm{m}^{2} ; p=0.48\right)$ was observed (Figures 7E-G). To investigate whether the specific alteration in spine neck morphology modified the relationship of distinct morphological parameters in the mouse model of Fragile X syndrome, we performed a detailed correlation analysis. In agreement with the fact that spine heads generally constitute the major bulk of spines (Arellano et al., 2007), spine head area correlated more strongly with total spine area than spine necks (Figures 8C,F). Nevertheless, there was still positive correlation between neck area and the total spine area (Figure 8C). Weak positive correlation was observed between neck width and spine area (Figure 8J). No correlation was found between neck length and head length (Figure 8G), neck length and head area (Figure $8 \mathbf{H}$ ), and only a very weak negative correlation was found 

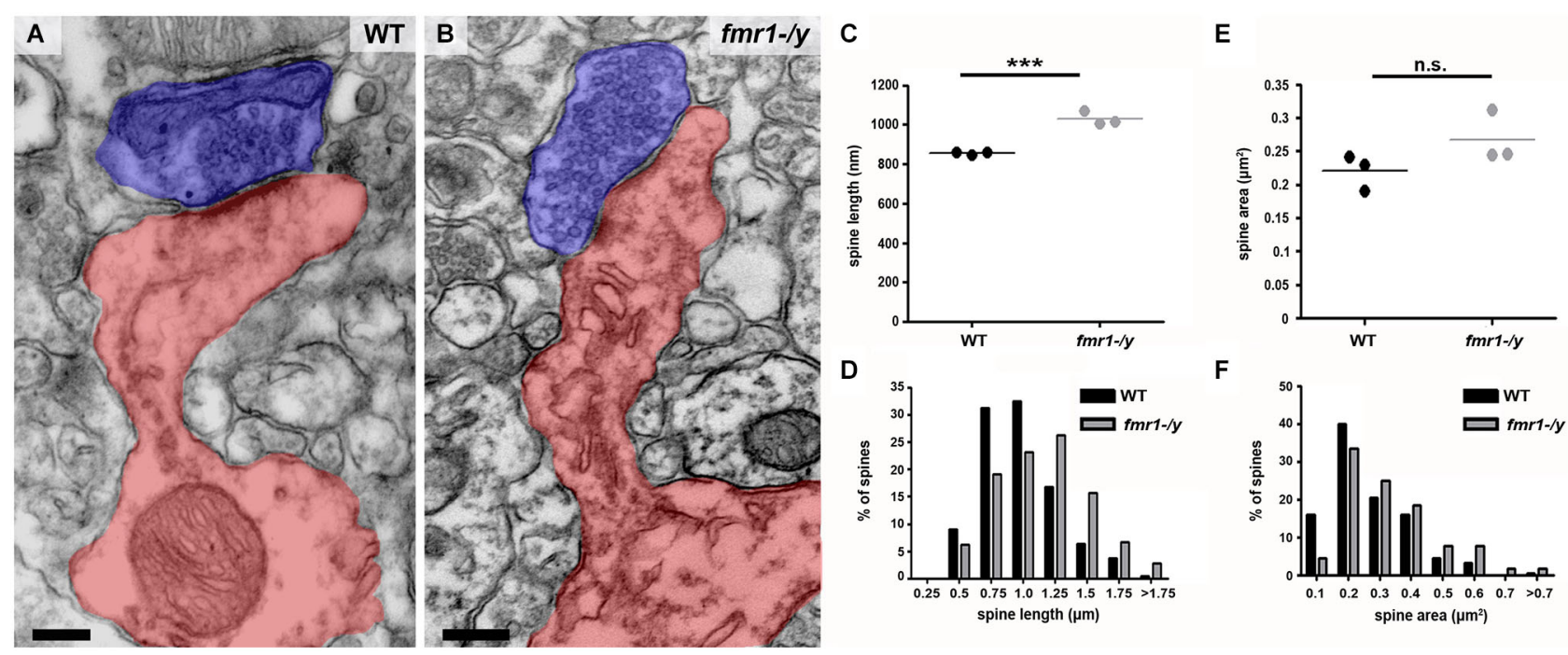

FIGURE 6 | Higher incidence of elongated spines in the accumbens of fmr1-/y mice. (A) Electron micrograph of a typical "mushroom" spine from the accumbens of a wild-type mouse. Scale bar $=100 \mathrm{~nm}$. (B) Electron micrograph of longer, spines found in the accumbens of an fmr1-/y mouse. Presynaptic terminals are highlighted in blue, postsynaptic spine(s) labeled in red. Scale bar $=100 \mathrm{~nm}$. (C) Analysis of mean spine length $(n=3 \mathrm{WT}$, $n=3 \mathrm{fmr} 1-/ \mathrm{y})$ uncovered the presence of longer spines in the fmr $1-/ y$ mice. Unpaired $t$-test, $p=0.001$. (D) Binned data from all 221 wild-type and 224 fmr1-/y spines reveals an increase in the number of long spines in fmr1-/y mice and a decrease in small spines compared to wild-type. Chi-squared test, $p<0.0001$. Although the difference in the mean area of wild-type and fmr1-/y spines did not reach statistical significance (E); 3 WT $\vee 3$ fmr1-/y mice, unpaired $t$-test, $p=0.157$ ), binning the data from all spines (221 WT $v$ $224 \mathrm{fmr} 1-/ \mathrm{y})$, revealed a rightward shift in the data distribution, due to a higher incidence of larger spines in fmr1-/y compared to wild-type (F). Chi-squared test, $p=0.0002$. between neck width and neck length (Figure 8I). These data are remarkably similar to data recently reported in spines of living neurons imaged in wild-type mouse hippocampus (Tønnesen et al., 2014). Importantly, while both genotypes showed similar correlation between neck length and neck area (Figure 8B), and head length and head area (Figure 8E), the strength of correlation was significantly stronger in the $f m r 1-/ y$ spines. Together with the distinct level of correlation between the head and neck lengths and the total spine length, these analyses point to the weighted contribution of the spine neck in determining total spine length (Figures 8A,D respectively). Collectively, these data (summarized in Table 1) reveal that FMRP loss leads to an increase in spine density and a specific elongation of the spine neck, but not the spine head in the accumbens.

Changes to the postsynapse may be mirrored by alterations in the presynapse, which can affect synaptic transmission and may explain some of the effects observed in our physiology experiments. To this end, we measured both the presynaptic active zone length and the total number of vesicles in 50 boutons per animal. These experiments revealed a similar correlation between active zone length and vesicle number in both strains (wild-type $R^{2}=0.49, f m r 1-/ y R^{2}=0.39$ ), but showed no difference in the presynaptic parameters measured. Active zone length was similar between strains (wild-type $=183.9 \pm 8.9 \mathrm{~nm}, \mathrm{fmr} 1-/ \mathrm{y}=$ $195.1 \pm 0.5 \mathrm{~nm} ; p=0.28$ ) and the total boutonal vesicle number showed no difference (wild-type $=30 \pm 0.3$, fmr $1-/ y=33 \pm 1.8$; $p=0.21$ ).

Given the importance of spine morphology on synaptic physiology (Nimchinsky et al., 2002; Sala and Segal, 2014; Tønnesen et al., 2014), the increased density and elongation of spines in the fmr1-/y accumbens is likely to contribute to the disrupted synaptic plasticity in the mouse model of Fragile $\mathrm{X}$ syndrome.

\section{Discussion}

In this study, we combined electrophysiological and electron microscopy methods and searched for functional and structural synaptic deficits in the nucleus accumbens of $f m r 1-/ y$ mice. Our main findings are that 1 / LTP is ablated at excitatory accumbens synapses of $f m r 1-/ y$ mice while there is a parallel increase of the AMPA/NMDA ratio and 2/ that adult fmrl-/y mice have significantly more excitatory synapses in the accumbens core and that spine necks were significantly longer in these mice.

Glutamatergic accumbens synapses express a wide array of mechanistically diverse forms of LTDs: NMDAR-dependent LTD, mGluR5-dependent and endocannabinoid-mediated retrograde LTD and presynaptic mGluR2/3 auto receptormediated LTD (Robbe et al., 2002b,c). In support of the idea that synaptic plasticity deficits occur in the accumbens of $f m r 1-/ y$ mice, we recently reported that the endocannabinoid/mGluR5 signaling complex and associated long-term depression are profoundly perturbed at accumbens synapses of fmr1-/y (Jung et al., 2012). Here we first established a STDP paradigm capable to induce a strong and reliable LTP of synaptic efficacy at excitatory accumbens synapses. Because a reliable STDP LTPinducing protocol at accumbens synapses was lacking (Ji and Martin, 2012), our study significantly expands previous work (Pennartz et al., 1993; Kombian and Malenka, 1994; Robbe et al., 2002b; Schotanus and Chergui, 2008b; Ji and Martin, 2012). 


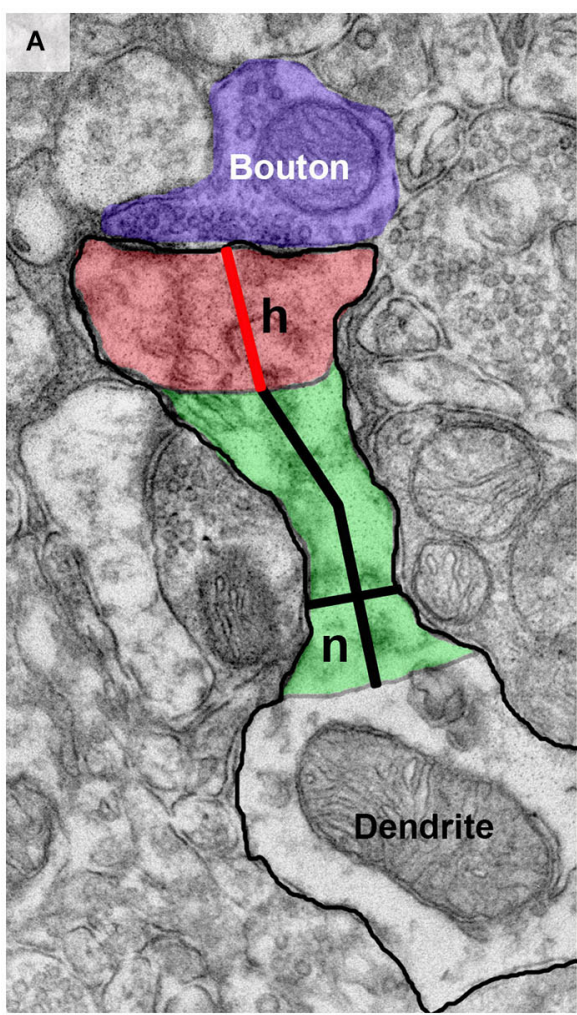

B

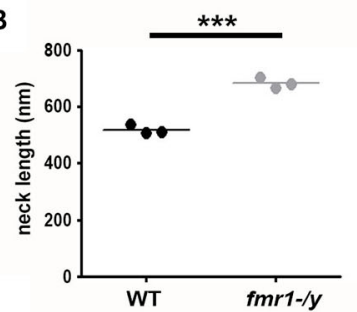

C

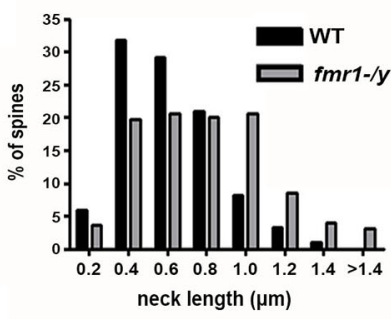

D

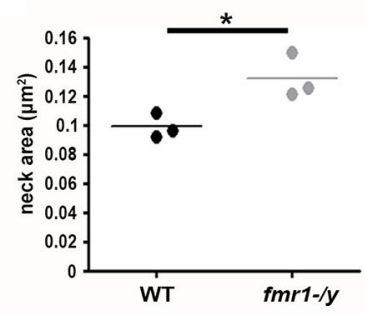

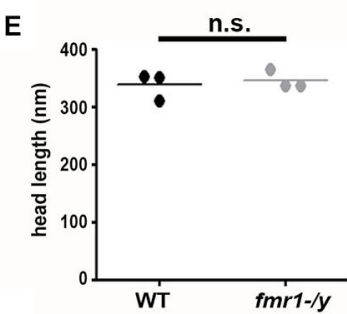

$\mathbf{F}$

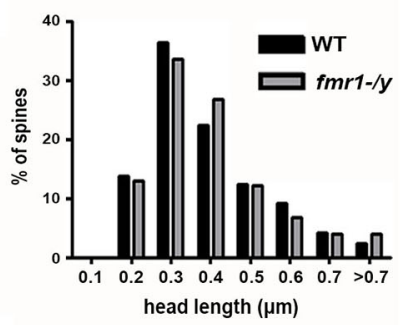

G

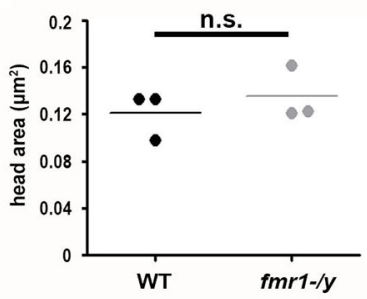

FIGURE 7 | Increased spine neck area and length in fmr1-/y accumbens. (A) Representative electron micrograph annotated with measurement parameters, including neck length (long black line), neck width (short black line), head length (red line), neck area (green) and head area (red). (B) Mean neck length of wild-type spines (221 spines, $n$ $=3$ mice) is significantly longer than fmr1-/y mice (224 spines, $n=3$ mice). Unpaired $t$-test, $p=0.0003$. (C) Binning all the spines from each genotype reveals a higher incidence of longer necks in the fmr1-/y mice compared to wild-type. Chi-squared test, $p<0.0001$. (D) The area of fmr1-y spine necks was significantly larger than those of wild-type spines. Unpaired t-test, $p=0.031$. In striking contrast to the changes in fmr1-/y spine necks, the spine heads were not different in length $(\mathbf{E})$; unpaired $t$-test $p=0.684$. (F); chi-squared test $p=0.795$ ) or in area (G); unpaired $t$-test $p=0.48$ ).
Accumbal STDP LTP was induced when the presynaptic activity precedes the spiking of the postsynaptic cell, following a hebbian rule (Caporale and Dan, 2008). In the present study GABA-A mediated transmission was blocked to isolate the glutamatergic synapses (see also Pawlak and Kerr, 2008). GABAergic IPSPs arising from fast-spiking, low thresholdspiking interneurons and collaterals can modify the backpropagating action potentials and the timing rules of STDP (Fino and Venance, 2010). Thus, future studies will be needed to test the importance of GABAergic activity on this LTP in pathophysiological conditions.

In wild-type mice, spike timing-dependent LTP was prevented by bath-application of D-AP5, showing its dependency on NMDAR. This result is in accordance with the majority of studies on STDP, where NMDAR-mediated LTP is found when the presynaptic activity precedes the spiking of the postsynaptic cell following a hebbian rule (Caporale and Dan, 2008 ; but see Paille et al., 2013).

Importantly, we found that LTP was ablated in the accumbens of fmr1-ly mice. This result is in line with reports of a lack of LTP in other brain structures of fmrl-/y mice (Meredith et al., 2007; Wilson and Cox, 2007; Suvrathan and Chattarji, 2011). A single previous study showed a deficient LTP in the PFC of fmr1-/y mice, which was attributed to a down regulation in dendritic L-type VGCC and unreliable dendritic $\mathrm{Ca}^{2+}$ signaling (Meredith et al., 2007). Noteworthy, L-type channels are not needed for the expression of LTP in neither dorsal nor ventral striatum (Ji and Martin, 2012; Paille et al., 2013), but rather necessary for the expression of timing-dependent long-term depression. Thus, a deregulation of L-type VGCC expression is not expected to have a negative effect on LTP.

A differential synaptic expression of NMDAR can set the threshold and capacity to express NMDAR-dependent LTP. This idea is supported by several studies in $f m r 1-/ y$ mice showing that defects in LTP coincide with decreased NMDAR protein levels or changes in the AMPA/NMDA ratio (Harlow et al., 2010; Yun and Trommer, 2011). Interestingly, FMRP binds GluN1, GluN2A, and GluN2B mRNAs and that the loss of FMRP leads to deregulated translation of these NMDAR subunits (Schütt et al., 2009; Edbauer et al., 2010) as well as abnormal expression of NMDAR (Krueger et al., 2011). Since a decreased NMDA expression can go along with deficits in LTP (Harlow et al., 2010; Bostrom et al., 2015), we tested whether the defects in 
A

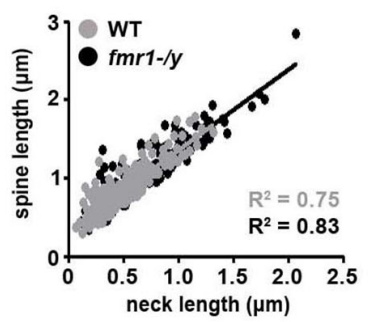

D

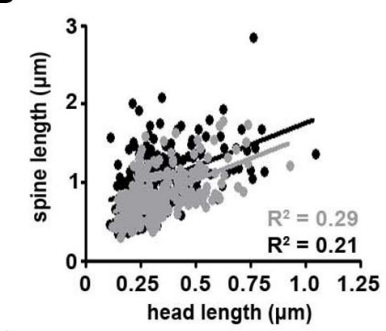

G

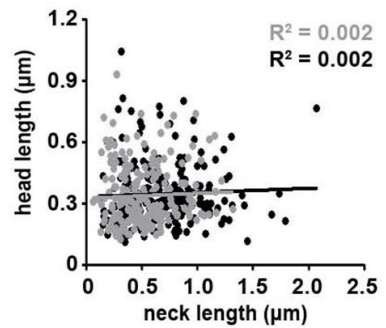

I

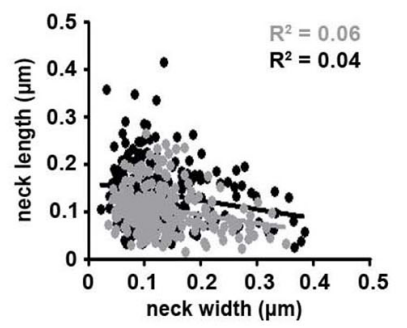

B

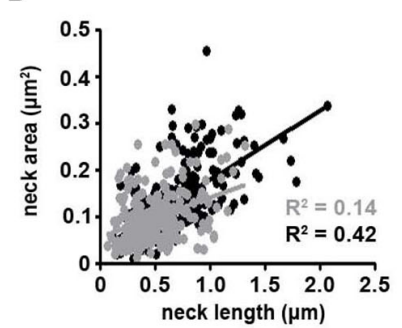

E

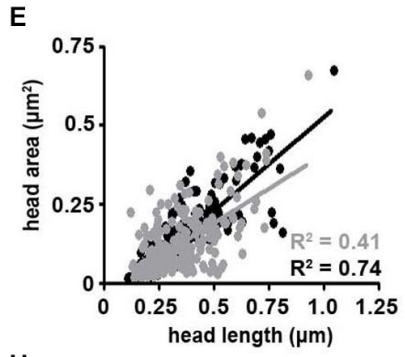

H

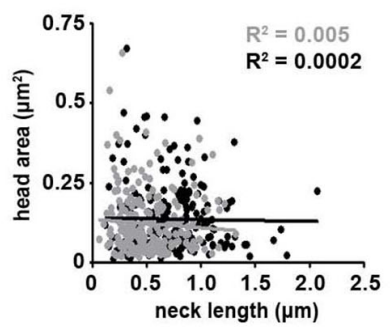

J

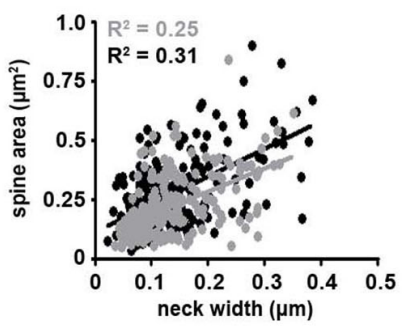

C

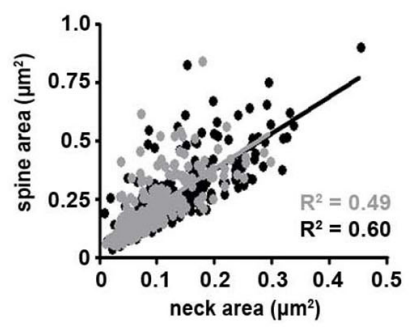

$\mathbf{F}$

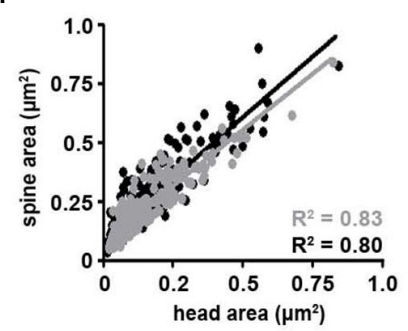

FIGURE 8 | Correlation analysis of morphological parameters of dendritic spines. Representative dot plots of spine morphological data. Data points representing individual spines from wild-type mice are highlighted with black dots and best-fit trend lines are black. Data points from fmr1-/y mice are highlighted in gray dots and best-fit trend lines are gray $(n=221$ wild-type spines, $n=224$ fmr1-/y spines). All Pearson $R^{2}$ values are color-coded as above.
LTP are accompanied by changes in AMPA/NMDA ratio. In agreement with several other studies (Harlow et al., 2010; Yun and Trommer, 2011), we found an increase of the AMPA/NMDA ratio in $f m r 1-/ y$ mice. Since the basal spontaneous AMPAR transmission and the size of the PSD length were unchanged (see Figures 8C,D and discussion below) this increase might indicate a reduction in NMDAR transmission. Our observation of reduced amplitude of basal spontaneous NMDAR synaptic currents supports this interpretation (Figure 4E). Alterations in the synaptic signaling machinery leading to the lack of LTP could be linked to structural abnormalities. Although the direct influence of spine morphology on LTP has not widely been studied, aberrant dendritic arborization and abnormal spine structures are associated with synaptic plasticity deficits in Fragile $\mathrm{X}$ as in other types of mental retardation (Penzes et al., 2011). We conducted an ultrastructural analysis by electron microscopy and discovered a number of spine alterations in adult $f m r 1-/ y$ mice. Firstly, we found that adult $f m r 1-/ y$ mice have significantly more excitatory synapses in the accumbens core. A recent observation based on light microscopic analysis revealed that the trend towards an increased spine density in fmrl-/y mice treated with cocaine, but not in vehicle did not reach statistical significance (Smith et al., 2014). In the present study, we used electron microscopy to unequivocally identify those dendritic spines, which receive asymmetrical synapses and the $3 \mathrm{D}$ analysis uncovered a significantly increased incidence 
TABLE 1 | Spine analysis parameters and results.

\begin{tabular}{|c|c|c|c|c|c|c|}
\hline & Genotype & Range & Mean & Median & Interquartile Range & n (spines/animals) \\
\hline PSD density & WT & $0.066-0.53$ & 0.25 & 0.23 & $0.2-0.3$ & 150 images/3 \\
\hline$p=0.049$ & fmr1-/y & $0.066-0.72$ & 0.32 & 0.3 & $0.23-0.39$ & 150 images/3 \\
\hline PSD length & WT & $106-639$ & 275 & 262 & $210-318$ & $300 / 3$ \\
\hline$p=0.42$ & fmr1-/y & $124-659$ & 289 & 273 & $216-346$ & $300 / 3$ \\
\hline Spine length & WT & $292-1783$ & 856 & 801 & $664-1057$ & $221 / 3$ \\
\hline$p=0.001$ & fmr1-/y & $339-2838$ & 1030 & 1012 & $745-1255$ & $224 / 3$ \\
\hline Spine area & WT & $0.05-0.84$ & 0.21 & 0.18 & $0.12-0.29$ & $221 / 3$ \\
\hline$p=0.157$ & fmr1-/y & $0.03-0.82$ & 0.28 & 0.25 & $0.17-0.35$ & $224 / 3$ \\
\hline Neck length & WT & $68-1319$ & 518 & 484 & $334-646$ & $221 / 3$ \\
\hline$p=0.0003$ & fmr1-/y & 122-2072 & 685 & 656 & $411-873$ & $224 / 3$ \\
\hline Neck area & WT & $0.01-0.3$ & 0.099 & 0.087 & $0.05-0.13$ & $221 / 3$ \\
\hline$p=0.031$ & fmr1-/y & $0.009-0.45$ & 0.13 & 0.11 & $0.08-0.17$ & $224 / 3$ \\
\hline Neck width & WT & $35-351$ & 136 & 121 & $89-166$ & $221 / 3$ \\
\hline$p=0.79$ & fmr1-/y & $23-384$ & 133 & 113 & $82-162$ & $224 / 3$ \\
\hline Head length & WT & $122-932$ & 338 & 299 & $229-421$ & $221 / 3$ \\
\hline$p=0.68$ & fmr1-/y & $112-1046$ & 346 & 243 & $243-413$ & $224 / 3$ \\
\hline Head area & WT & $0.017-0.66$ & 0.12 & 0.089 & $0.05-0.17$ & $221 / 3$ \\
\hline$p=0.48$ & fmr1-/y & $0.011-0.67$ & 0.14 & 0.1 & $0.06-0.18$ & $224 / 3$ \\
\hline
\end{tabular}

Length in $\mathrm{nm}$, area in $\mathrm{um}^{2}$ and density in $\mathrm{PSD} / \mathrm{um}^{2}$.

of unusually long spines in $f m r 1-/ y$ mice. These findings of extra spines and elongated spines in the $f m r 1-/ y$ mice, are in agreement with the long filopodial spines observed in other brain areas of $\mathrm{fmr1-} / \mathrm{y}$ mice (Meredith et al., 2007; Cruz-Martín et al., 2010; He and Portera-Cailliau, 2013) and in Fragile X postmortem tissue (Irwin et al., 2001), and can be interpreted as spine immaturity, due to a deficit in synapse pruning (Bagni and Greenough, 2005). In fact, many of our spine measurements are similar to those reported in various studies from distinct brain regions. For example, we found that spine neck width was the same between genotypes, which is consistent with findings in the cerebellum of fmrl-/y mice (Koekkoek et al., 2005). Furthermore, in both genotypes, neck diameter showed a weak, but significant correlation with total spine volume, which was previously shown in the mouse neocortex (Arellano et al., 2007).

Given our discovery of ablated LTP in the fmr1- $/ y$ mice, it is interesting to note that spine necks were significantly longer in these mice. It may therefore be reasonable to speculate that the increased incidence of long immature-appearing spines could be due to a lack of spine pruning, combined with a loss of LTPinduced spine shrinkage. It is also important to note that the spine alteration was specifically observed within the neck and not the head compartment. Previous work in the mouse neocortex has shown that the spine neck length negatively correlated with the strength of somatically recorded membrane potential changes following glutamate uncaging next to the spine head (Araya et al., 2006). The study showed that the effect was independent of spine proximity to the soma or spine head size, as both long and short spines had similar head sizes. This shows that specific changes in spine neck length are sufficient to filter synaptic activity. Therefore, a higher incidence of long necked spines in the fmr1-/y mice may lead to increased filtering of synaptic inputs resulting in a lack of LTP.

So far it cannot be determined, whether the structural differences are a cause or a consequence of the lack of LTP in $f m r 1-/ y$. Recent studies in the neocortex reported a faster turnover of dendritic spines in fmrl-/y mice (Cruz-Martín et al., 2010; Padmashri et al., 2013). This could be interpreted as a failure of spine stabilization due to the lack of LTP. Our electron microscopy data could be a snapshot of a similar alternation in the accumbens. In addition, the lack of LTD in the nucleus accumbens (Jung et al., 2012), which has been shown to be necessary for the pruning of neurons in other brain structures (Bastrikova et al., 2008) could prevent the elimination of spines and lead to the overabundance of long and immature spines in $f m r l-/ y$ mice. In return, the changes in the density and geometry of postsynaptic spines most probably have an influence on the chemical and electrical compartmentalization and thereby on action potential backpropagation and synaptic integration (Tønnesen et al., 2014; Wijetunge et al., 2014).

Fragile $\mathrm{X}$ patients show behavioral symptoms such as attention deficit and hyperactivity, social anxiety and an overall stressful disposition and importantly, fmrl-/y mice show corresponding behaviors (Kooy, 2003; Tranfaglia, 2011). Together, our study reveals new structural and functional alterations in the nucleus accumbens of $f m r 1-/ y$ mice and suggests potential synaptic substrates of social interaction deficits and emotional problems observed in Fragile X.

\section{Acknowledgments}

This work was supported by the FRAXA Foundation (OJM, MS and DN), a NARSAD 2010 Independent Investigator Grant given by the Brain and Behavior Research Foundation (OJM), INSERM (OJM), ANR-Blanc France-Taiwan RescueMemo (OJM). This study was also supported by The Momentum Program (LP201354/2013) of the Hungarian Academy of Sciences and by the European Research Council Grant 243153 (IK). IK is a recipient of the Wellcome Trust International Senior Research Fellowship (090946/Z/09/Z). CMH was a recipient of a European Molecular 
Biology Organization long-term fellowship. The authors acknowledge FRAXA research foundation (Dr. D. Nelson, Baylor College of Medicine) for providing the fmr1 KO2 mice. The technical assistance of E. Tischler, G. Goda, B. Pinter, D. Thongkham and J. Lockney is also acknowledged. We

\section{References}

Araya, R., Eisenthal, K. B., and Yuste, R. (2006). Dendritic spines linearize the summation of excitatory potentials. Proc. Natl. Acad. Sci. U S A 103, 1879918804. doi: $10.1073 /$ pnas. 0609225103

Araya, R., Vogels, T. P., and Yuste, R. (2014). Activity-dependent dendritic spine neck changes are correlated with synaptic strength. Proc. Natl. Acad. Sci. U S A 111, E2895-E2904. doi: 10.1073/pnas.1321869111

Arellano, J. I., Benavides-Piccione, R., Defelipe, J., and Yuste, R. (2007). Ultrastructure of dendritic spines: correlation between synaptic and spine morphologies. Front. Neurosci. 1, 131-143. doi: 10.3389/neuro.01.1.1. 010.2007

Bagni, C., and Greenough, W. T. (2005). From mRNP trafficking to spine dysmorphogenesis: the roots of fragile X syndrome. Nat. Rev. Neurosci. 6, 376-387. doi: 10.1038/nrn1667

Bastrikova, N., Gardner, G., Reece, J. M., Jeromin, A., and Dudek, S. M. (2008). Synapse elimination accompanies functional plasticity in hippocampal neurons. Proc. Natl. Acad. Sci. U S A 105, 3123-3127. doi: 10.1073/pnas. 0800027105

Bear, M. F., Huber, K. M., and Warren, S. T. (2004). The mGluR theory of fragile X mental retardation. Trends Neurosci. 27, 370-377. doi: 10.1016/j.tins.2004. 04.009

Boda, B., Mendez, P., Boury-Jamot, B., Magara, F., and Muller, D. (2014). Reversal of activity-mediated spine dynamics and learning impairment in a mouse model of Fragile X syndrome. Eur. J. Neurosci. 39, 1130-1137. doi: 10.1111/ejn. 12488

Bostrom, C. A., Majaess, N.-M., Morch, K., White, E., Eadie, B. D., and Christie, B. R. (2015). Rescue of NMDAR-Dependent synaptic plasticity in Fmr1 knock-out mice. Cereb. Cortex 25, 271-279. doi: 10.1093/cercor/ bht 237

Caporale, N., and Dan, Y. (2008). Spike timing-dependent plasticity: a Hebbian learning rule. Annu. Rev. Neurosci. 31, 25-46. doi: 10.1146/annurev.neuro.31. 060407.125639

Chen, T., Lu, J.-S., Song, Q., Liu, M.-G., Koga, K., Descalzi, G., et al. (2014). Pharmacological rescue of cortical synaptic and network potentiation in a mouse model for fragile X syndrome. Neuropsychopharmacology 39, 1955-1967. doi: 10.1038/npp.2014.44

Comery, T. A., Harris, J. B., Willems, P. J., Oostra, B. A., Irwin, S. A., Weiler, I. J., et al. (1997). Abnormal dendritic spines in fragile X knockout mice: maturation and pruning deficits. Proc. Natl. Acad. Sci. U S A 94, 5401-5404. doi: 10. 1073/pnas.94.10.5401

Cruz-Martín, A., Crespo, M., and Portera-Cailliau, C. (2010). Delayed stabilization of dendritic spines in fragile X mice. J. Neurosci. 30, 7793-7803. doi: 10. 1523/JNEUROSCI.0577-10.2010

Dan, Y., and Poo, M.-M. (2004). Spike timing-dependent plasticity of neural circuits. Neuron 44, 23-30. doi: 10.1016/j.neuron.2004.09.007

Darnell, J. C., Van Driesche, S. J., Zhang, C., Hung, K. Y. S., Mele, A., Fraser, C. E., et al. (2011). FMRP stalls ribosomal translocation on mRNAs linked to synaptic function and autism. Cell 146, 247-261. doi: 10.1016/j.cell.2011. 06.013

de Vries, B. B. A., Halley, D. J. J., Oostra, B. A., and Niermeijer, M. F. (1998). The fragile X syndrome. J. Med. Genet. 23, 579-589. doi: 10.1136/jmg. 35.7.579

Dölen, G., Darvishzadeh, A., Huang, K. W., and Malenka, R. C. (2013). Social reward requires coordinated activity of nucleus accumbens oxytocin and serotonin. Nature 501, 179-184. doi: 10.1038/nature12518

Edbauer, D., Neilson, J. R., Foster, K. A., Wang, C.-F., Seeburg, D. P., Batterton, M. N., et al. (2010). Regulation of synaptic structure and function by FMRPassociated microRNAs miR-125b and miR-132. Neuron 65, 373-384. doi: 10. 1016/j.neuron.2010.01.005 thank members from the Manzoni and Chavis laboratories for discussions, Dr. L. Venance for advices on STDP and the National Institute of Mental Health's Chemical Synthesis and Drug Supply Program (Rockville, MD, USA) for providing DNQX and D-APV.

Fino, E., Glowinski, J., and Venance, L. (2005). Bidirectional activity-dependent plasticity at corticostriatal synapses. J. Neurosci. 25, 11279-11287. doi: 10. 1523/jneurosci.4476-05.2005

Fino, E., and Venance, L. (2010). Spike-timing-dependent plasticity in the striatum. Front. Synaptic. Neurosci. 2:6. doi: 10.3389/fnsyn.2010. 00006

Franklin, A. V., King, M. K., Palomo, V., Martinez, A., McMahon, L. L., and Jope, R. S. (2014). Glycogen synthase kinase-3 inhibitors reverse deficits in longterm potentiation and cognition in fragile X mice. Biol. Psychiatry 75, 198-206. doi: 10.1016/j.biopsych.2013.08.003

Geinisman, Y., Gundersen, H. J., van der Zee, E., and West, M. J. (1996). Unbiased stereological estimation of the total number of synapses in a brain region. J. Neurocytol. 25, 805-819. doi: 10.1007/bf02284843

Gipson, C. D., Kupchik, Y. M., and Kalivas, P. W. (2014). Rapid, transient synaptic plasticity in addiction. Neuropharmacology 76(Pt. B), 276-286. doi: 10.1016/j. neuropharm.2013.04.032

Gocel, J., and Larson, J. (2012). Synaptic NMDA receptor-mediated currents in anterior piriform cortex are reduced in the adult fragile X mouse. Neuroscience 221, 170-181. doi: 10.1016/j.neuroscience.2012. 06.052

Grueter, B. A., Brasnjo, G., and Malenka, R. C. (2010). Postsynaptic TRPV1 triggers cell type-specific long-term depression in the nucleus accumbens. Nat. Neurosci. 13, 1519-1525. doi: 10.1038/nn.2685

Grueter, B. A., Rothwell, P. E., and Malenka, R. C. (2012). Integrating synaptic plasticity and striatal circuit function in addiction. Curr. Opin. Neurobiol. 22, 545-551 doi: 10.1016/j.conb.2011.09.009

Gunaydin, L. A., Grosenick, L., Finkelstein, J. C., Kauvar, I. V., Fenno, L. E., Adhikari, A., et al. (2014). Natural neural projection dynamics underlying social behavior. Cell 157, 1535-1551. doi: 10.1016/j.cell.2014. 05.017

Harlow, E. G., Till, S. M., Russell, T. A., Wijetunge, L. S., Kind, P., and Contractor, A. (2010). Critical period plasticity is disrupted in the barrel cortex of FMR1 knockout mice. Neuron 65, 385-398. doi: 10.1016/j.neuron.2010. 01.024

He, C. X., and Portera-Cailliau, C. (2013). The trouble with spines in fragile X syndrome: density, maturity and plasticity. Neuroscience 251, 120-128. doi: 10. 1016/j.neuroscience.2012.03.049

Irwin, S. A., Galvez, R., and Greenough, W. T. (2000). Dendritic spine structural anomalies in fragile-X mental retardation syndrome. Cereb. Cortex 10, 10381044. doi: 10.1093/cercor/10.10.1038

Irwin, S. A., Patel, B., Idupulapati, M., Harris, J. B., Crisostomo, R. A., Larsen, B. P., et al. (2001). Abnormal dendritic spine characteristics in the temporal and visual cortices of patients with fragile- $\mathrm{X}$ syndrome: a quantitative examination. Am. J. Med. Genet. 98, 161-167. doi: 10.1002/10968628(20010115)98:2<161::aid-ajmg1025>3.0.co;2-b

Ji, X., and Martin, G. E. (2012). New rules governing synaptic plasticity in core nucleus accumbens medium spiny neurons. Eur. J. Neurosci. 36, 3615-3627. doi: 10.1111 /ejn.12002

Jung, K., Sepers, M., Henstridge, C. M., Lassalle, O., Neuhofer, D., Martin, H., et al. (2012). Uncoupling of the endocannabinoid signalling complex in a mouse model of fragile X syndrome. Nat. Commun. 3:1080. doi: 10.1038/ncomms 2045

Kasanetz, F., and Manzoni, O. J. (2009). Maturation of excitatory synaptic transmission of the rat nucleus accumbens from juvenile to adult. J. Neurophysiol. 101, 2516-2527. doi: 10.1152/jn.91039.2008

Koekkoek, S. K., Yamaguchi, K., Milojkovic, B. A., Dortland, B. R., Ruigrok, T. J., Maex, R., et al. (2005). Deletion of FMR1 in Purkinje cells enhances parallel fiber LTD, enlarges spines, and attenuates cerebellar eyelid conditioning in Fragile X syndrome. Neuron 47, 339-352. doi: 10.1016/j.neuron.2005. 07.005 
Kombian, S. B., and Malenka, R. C. (1994). Simultaneous LTP of non-NMDAand LTD of NMDA-receptor-mediated responses in the nucleus accumbens. Nature 368, 242-246. doi: 10.1038/368242a0

Kooy, R. F. (2003). Of mice and the fragile X syndrome. Trends Genet. 19, 148-154. doi: 10.1016/s0168-9525(03)00017-9

Krueger, D. D., Osterweil, E. K., Chen, S. P., Tye, L. D., and Bear, M. F. (2011). Cognitive dysfunction and prefrontal synaptic abnormalities in a mouse model of fragile X syndrome. Proc. Natl. Acad. Sci. U S A 108, 2587-2592. doi: 10. 1073/pnas.1013855108

Markram, H., Lübke, J., Frotscher, M., and Sakmann, B. (1997). Regulation of synaptic efficacy by coincidence of Postsynaptic APs and EPSPs. Science 275, 213-215. doi: $10.1126 /$ science.275.5297.213

Martin, B. S., and Huntsman, M. M. (2012). Pathological plasticity in fragile X syndrome. Neural Plast. 2012:275630. doi: 10.1155/2012/275630

Martin, H. G. S., and Manzoni, O. J. (2014). Late onset deficits in synaptic plasticity in the valproic acid rat model of autism. Front. Cell. Neurosci. 8:23. doi: 10. 3389/fncel.2014.00023

Maurin, T., Zongaro, S., and Bardoni, B. (2014). Fragile X syndrome: from molecular pathology to therapy. Neurosci. Biobehav. Rev. 46, 242-255. doi: 10. 1016/j.neubiorev.2014.01.006

McGinty, V. B., and Grace, A. A. (2008). Selective activation of medial prefrontal-to-accumbens projection neurons by amygdala stimulation and Pavlovian conditioned stimuli. Cereb. Cortex 18, 1961-1972. doi: 10.1093/ cercor/bhm 223

Meredith, R. M., Holmgren, C. D., Weidum, M., Burnashev, N., and Mansvelder, H. D. (2007). Increased threshold for spike-timing-dependent plasticity is caused by unreliable calcium signaling in mice lacking fragile X gene FMR1. Neuron 54, 627-638. doi: 10.1016/j.neuron.2007.04.028

Nevian, T., and Sakmann, B. (2006). Spine $\mathrm{Ca}^{2+}$ signaling in spike-timingdependent plasticity. J. Neurosci. 26, 11001-11013. doi: 10.1523/jneurosci. 1749-06.2006

Nimchinsky, E. A., Sabatini, B. L., and Svoboda, K. (2002). Structure and function of dendritic spines. Annu. Rev. Physiol. 64, 313-353. doi: 10.1146/annurev. physiol.64.081501.160008

Oddi, D., Crusio, W. E., D’Amato, F. R., and Pietropaolo, S. (2013). Monogenic mouse models of social dysfunction: implications for autism. Behav. Brain Res. 251, 75-84. doi: 10.1016/j.bbr.2013.01.002

Padmashri, R., Reiner, B. C., Suresh, A., Spartz, E., and Dunaevsky, A. (2013). Altered structural and functional synaptic plasticity with motor skill learning in a mouse model of fragile X syndrome. J. Neurosci. 33, 19715-19723. doi: 10. 1523/JNEUROSCI.2514-13.2013

Paille, V., Fino, E., Du, K., Morera-Herreras, T., Perez, S., Kotaleski, J. H., et al. (2013). GABAergic circuits control spike-timing-dependent plasticity. J. Neurosci. 33, 9353-9363. doi: 10.1523/JNEUROSCI.5796-12.2013

Papp, E., Borhegyi, Z., Tomioka, R., Rockland, K. S., Mody, I., and Freund, T. F. (2012). Glutamatergic input from specific sources influences the nucleus accumbens-ventral pallidum information flow. Brain Struct. Funct. 217, 37-48. doi: 10.1007/s00429-011-0331-Z

Pawlak, V., and Kerr, J. N. D. (2008). Dopamine receptor activation is required for corticostriatal spike-timing-dependent plasticity. J. Neurosci. 28, 2435-2446. doi: 10.1523/JNEUROSCI.4402-07.2008

Pennartz, C. M., Ameerun, R. F., Groenewegen, H. J., and Lopes da Silva, F. H. (1993). Synaptic plasticity in an in vitro slice preparation of the rat nucleus accumbens. J. Eur. Neurosci. 5, 107-117. doi: 10.1111/j.1460-9568. 1993.tb00475.x

Penzes, P., Cahill, M. E., Jones, K., VanLeeuwen, J.-E., and Woolfrey, K. M. (2011). Dendritic spine pathology in neuropsychiatric disorders. Nat. Neurosci. 14, 285-293. doi: 10.1038/nn.2741

Robbe, D., Alonso, G., Chaumont, S., Bockaert, J., and Manzoni, O. J. (2002a). Role of $\mathrm{p} / \mathrm{q}-\mathrm{Ca}^{2+}$ channels in metabotropic glutamate receptor $2 / 3$-dependent presynaptic long-term depression at nucleus accumbens synapses. J. Neurosci. 22, 4346-4356.

Robbe, D., Bockaert, J., and Manzoni, O. J. (2002b). Metabotropic glutamate receptor 2/3-dependent long-term depression in the nucleus accumbens is blocked in morphine withdrawn mice. Eur. J. Neurosci. 16, 2231-2235. doi: 10. 1046/j.1460-9568.2002.02273.x

Robbe, D., Kopf, M., Remaury, A., Bockaert, J., and Manzoni, O. J. (2002c). Endogenous cannabinoids mediate long-term synaptic depression in the nucleus accumbens. Proc. Natl. Acad. Sci. U S A 99, 8384-8388. doi: 10. 1073/pnas.122149199

Ronesi, J. A., and Huber, K. M. (2008). Metabotropic glutamate receptors and fragile $\mathrm{x}$ mental retardation protein: partners in translational regulation at the synapse. Sci. Signal. 1:pe6. doi: 10.1126/stke.15pe6

Sala, C., and Segal, M. (2014). Dendritic spines: the locus of structural and functional plasticity. Physiol. Rev. 94, 141-188. doi: 10.1152/physrev.00012. 2013

Schotanus, S. M., and Chergui, K. (2008a). Long-term potentiation in the nucleus accumbens requires both NR2A- and NR2B-containing N-methyl-D-aspartate receptors. Eur. J. Neurosci. 27, 1957-1964. doi: 10.1111/j.1460-9568.2008. 06173.x

Schotanus, S. M., and Chergui, K. (2008b). Dopamine D1 receptors and group I metabotropic glutamate receptors contribute to the induction of long-term potentiation in the nucleus accumbens. Neuropharmacology 54, 837-844. doi: 10.1016/j.neuropharm.2007.12.012

Schramm, N. L., Egli, R. E., and Winder, D. G. (2002). LTP in the mouse nucleus accumbens is developmentally regulated. Synapse 45, 213-219. doi: 10. 1002/syn.10104

Schütt, J., Falley, K., Richter, D., Kreienkamp, H.-J., and Kindler, S. (2009). Fragile $\mathrm{X}$ mental retardation protein regulates the levels of scaffold proteins and glutamate receptors in postsynaptic densities. J. Biol. Chem. 284, 25479-25487. doi: $10.1074 /$ jbc.M109.042663

Sesack, S. R., and Grace, A. A. (2010). Cortico-Basal Ganglia reward network: microcircuitry. Neuropsychopharmacology 35, 27-47. doi: 10.1038/npp. 2009.93

Shen, W., Flajolet, M., Greengard, P., and Surmeier, D. J. (2008). Dichotomous dopaminergic control of striatal synaptic plasticity. Science 321, 848-851. doi: 10.1126/science.1160575

Sidorov, M. S., Auerbach, B. D., and Bear, M. F. (2013). Fragile X mental retardation protein and synaptic plasticity. Mol. Brain 6:15. doi: 10.1186/17566606-6-15

Smith, L. N., Jedynak, J. P., Fontenot, M. R., Hale, C. F., Dietz, K. C., Taniguchi, M., et al. (2014). Fragile $\mathrm{X}$ mental retardation protein regulates synaptic and behavioral plasticity to repeated cocaine administration. Neuron 82, 645-658. doi: 10.1016/j.neuron.2014.03.028

Suvrathan, A., and Chattarji, S. (2011). Fragile X syndrome and the amygdala. Curr. Opin. Neurobiol. 21, 509-515. doi: 10.1016/j.conb.2011. 04.005

Thomazeau, A., Lassalle, O., Iafrati, J., Souchet, B., Guedj, F., Janel, N., et al. (2014). Prefrontal deficits in a murine model overexpressing the down syndrome candidate gene dyrk1a. J. Neurosci. 34, 1138-1147. doi: 10.1523/JNEUROSCI. 2852-13.2014

Tønnesen, J., Katona, G., Rózsa, B., and Nägerl, U. V. (2014). Spine neck plasticity regulates compartmentalization of synapses. Nat. Neurosci. 17, 678-685. doi: $10.1038 / \mathrm{nn} .3682$

Tranfaglia, M. R. (2011). The psychiatric presentation of fragile $\mathrm{x}$ : evolution of the diagnosis and treatment of the psychiatric comorbidities of fragile X syndrome. Dev. Neurosci. 33, 337-348. doi: 10.1159/000329421

Verkerk, A. J., Pieretti, M., Sutcliffe, J. S., Fu, Y. H., Kuhl, D. P., Pizzuti, A., et al. (1991). Identification of a gene (FMR-1) containing a CGG repeat coincident with a breakpoint cluster region exhibiting length variation in fragile X syndrome. Cell 65, 905-914. doi: 10.1016/0092-8674(91)90397-h

Wallace, D. L., Han, M. H., Graham, D. L., Green, T. A., Vialou, V., Iñiguez, S. D., et al. (2009). CREB regulation of nucleus accumbens excitability mediates social isolation-induced behavioral deficits. Nat. Neurosci. 12, 200-209. doi: 10. 1038/nn.2257

Wijetunge, L. S., Angibaud, J., Frick, A., Kind, P. C., and Nägerl, U. V. (2014). Stimulated emission depletion (STED) microscopy reveals nanoscale defects in the developmental trajectory of dendritic spine morphogenesis in a mouse model of fragile X syndrome. J. Neurosci. 34, 6405-6412. doi: 10. 1523/JNEUROSCI.2974-14.2014

Wilson, B. M., and Cox, C. L. (2007). Absence of metabotropic glutamate receptormediated plasticity in the neocortex of fragile X mice. Proc. Natl. Acad. Sci. U S A 104, 2454-2459. doi: 10.1073/pnas.0610875104

Yang, S., Yang, S., Park, J.-S., Kirkwood, A., and Bao, S. (2014). Failed stabilization for long-term potentiation in the auditory cortex of FMR1 knockout mice. PLoS One 9:e104691. doi: 10.1371/journal.pone.0104691 
Yun, S. H., and Trommer, B. L. (2011). Fragile X mice: reduced long-term potentiation and N-Methyl-D-Aspartate receptor-mediated neurotransmission in dentate gyrus. J. Neurosci. Res. 89, 176-182. doi: 10.1002/jnr.22546

Conflict of Interest Statement: The authors declare that the research was conducted in the absence of any commercial or financial relationships that could be construed as a potential conflict of interest.
Copyright (c) 2015 Neuhofer, Henstridge, Dudok, Sepers, Lassalle, Katona and Manzoni. This is an open-access article distributed under the terms of the Creative Commons Attribution License (CC BY). The use, distribution and reproduction in other forums is permitted, provided the original author(s) or licensor are credited and that the original publication in this journal is cited, in accordance with accepted academic practice. No use, distribution or reproduction is permitted which does not comply with these terms. 